\title{
Noise Scaling and Community Noise Metrics for the Hybrid Wing Body Aircraft
}

\author{
Casey L. Burley ${ }^{1}$, Thomas F. Brooks ${ }^{2}$, Florence V. Hutcheson ${ }^{1}$, Michael J. Doty ${ }^{1}$, Leonard V. Lopes ${ }^{3}$, Craig L. \\ Nickol $^{4}$, Dan D. Vicroy ${ }^{5}$ \\ NASA Langley Research Center, Hampton, VA 23681 USA \\ D. Stuart Pope ${ }^{6}$ \\ Analytical Services and Material, Hampton, VA 23681 USA
}

\begin{abstract}
An aircraft system noise assessment was performed for the hybrid wing body aircraft concept, known as the N2A-EXTE. This assessment is a result of an effort by NASA to explore a realistic HWB design that has the potential to substantially reduce noise and fuel burn. Under contract to NASA, Boeing designed the aircraft using practical aircraft design principles with incorporation of noise technologies projected to be available in the 2020 timeframe. NASA tested a $5.8 \%$ scale-model of the design in the NASA Langley 14- by 22Foot Subsonic Tunnel to provide source noise directivity and installation effects for aircraft engine and airframe configurations. Analysis permitted direct scaling of the model-scale jet, airframe, and engine shielding effect measurements to full-scale. Use of these in combination with ANOPP predictions enabled computations of the cumulative (CUM) noise margins relative to FAA Stage 4 limits. The CUM margins were computed for a baseline N2A-EXTE configuration and for configurations with added noise reduction strategies. The strategies include reduced approach speed, over-the-rotor liner and soft-vane fan technologies, vertical tail placement and orientation, and modified landing gear designs with fairings. Combining the inherent HWB engine shielding by the airframe with added noise technologies, the cumulative noise was assessed at $38.7 \mathrm{~dB}$ below FAA Stage 4 certification level, just $3.3 \mathrm{~dB}$ short of the NASA $\mathrm{N}+2$ goal of $42 \mathrm{~dB}$. This new result shows that the NASA $\mathrm{N}+2$ goal is approachable and that significant reduction in overall aircraft noise is possible through configurations with noise reduction technologies and operational changes.
\end{abstract}

\section{Nomenclature}

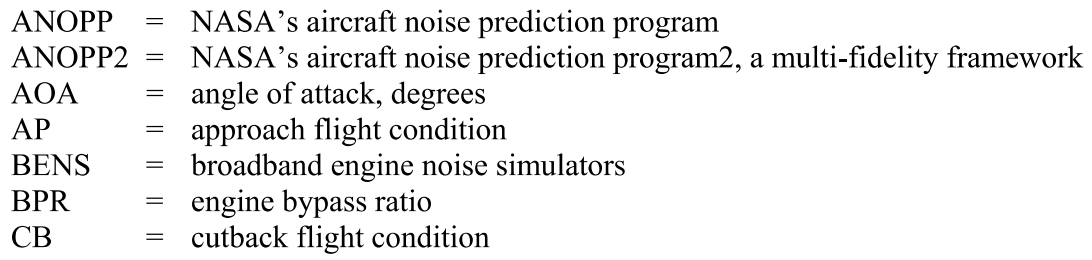

\footnotetext{
${ }^{1}$ Senior Research Engineer, Aeroacoustics Branch, Senior Member AIAA.

${ }^{2}$ Senior Research Scientist, Aeroacoustics Branch, Fellow AIAA.

${ }^{3}$ Research Engineer, Aeroacoustics Branch, Member AIAA.

${ }^{4}$ Senior Research Engineer, Aeronautical Systems Analysis Branch, Senior Member AIAA

${ }^{5}$ Senior Research Engineer, Flight Dynamics Branch, Associate Fellow AIAA.

${ }^{6}$ Senior Scientist, Analytical Services and Materials.
} 


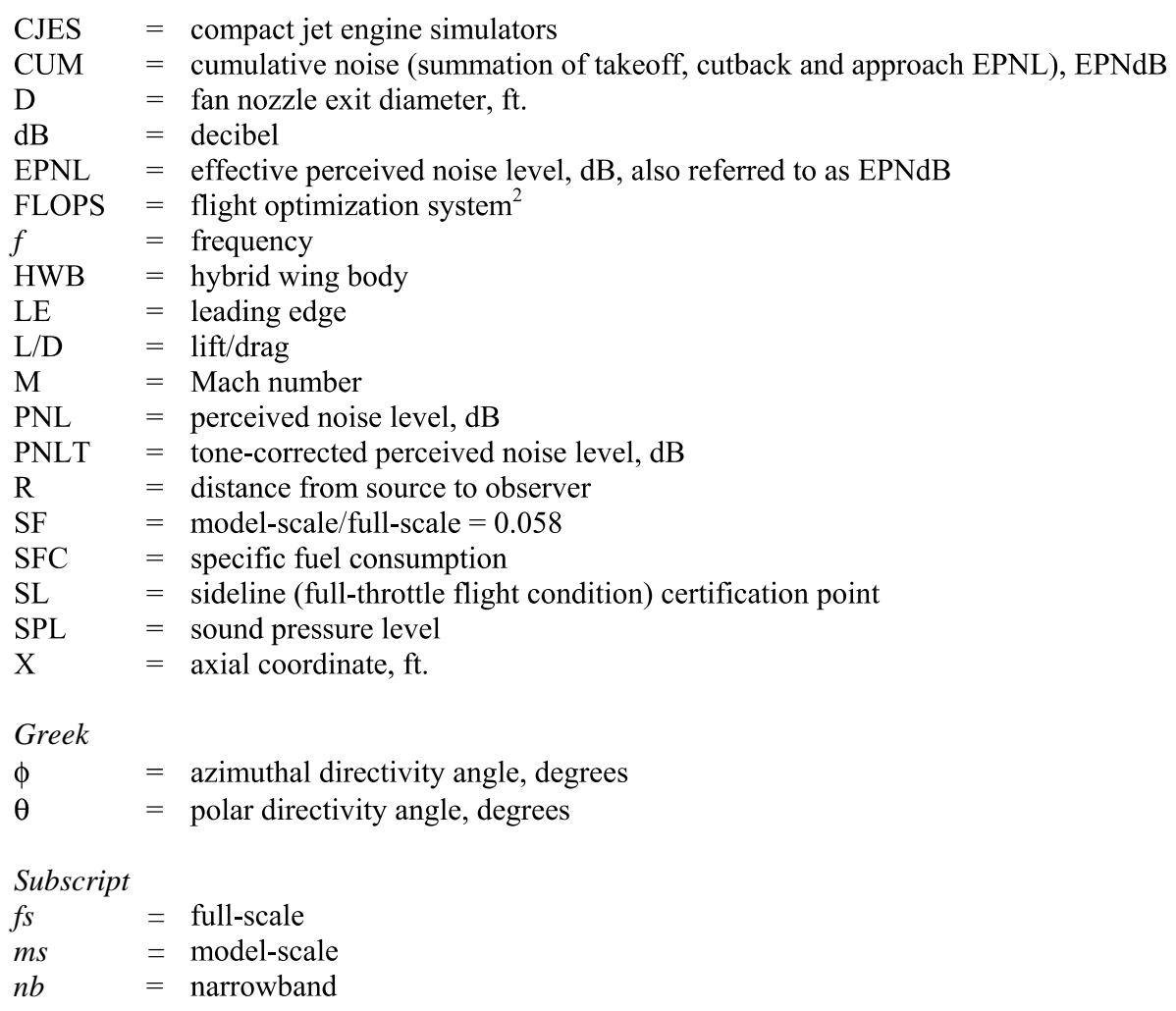

\section{Introduction}

Aviation generated noise has been and remains a significant issue for communities surrounding airports. Solutions to address aviation noise and its impact on the community have included improved land use planning near airports, more stringent aircraft noise certification regulations, and specific low noise operations near and in the vicinity of airports. In addition to solutions to mitigate the noise on the ground, there has been significant research and development to reduce the noise at its source, i.e. design of the engine and airframe to reduce noise. One aircraft design that has shown compelling potential to reduce aircraft noise is the hybrid-wing-body (HWB) aircraft. The HWB has been under study for a number of years in part due to its potential for reduced noise as well as fuel burn. ${ }^{1-6}$ Its potential for major reduction in noise levels with respect to current tube-and-wing aircraft has been shown by a number of studies. In Reference 6, a HWB aircraft with aggressive engine and airframe technologies combined with low noise operations was predicted to have a cumulative (CUM) Effective Perceived Noise Level (EPNL) noise margin of about $43 \mathrm{EPNdB}$ relative to Stage 4 noise limits. (CUM is summation of the EPNL determined at the approach, sideline and flyover certification points). This result has received much attention due to the relatively large noise reduction potential shown by combining changes in aircraft configuration with application of noise reduction technologies.

\footnotetext{
${ }^{2}$ Senior Research Engineer, Aeroacoustics Branch, Senior Member AIAA.

${ }^{2}$ Senior Research Scientist, Aeroacoustics Branch, Fellow AIAA.

${ }^{3}$ Research Engineer, Aeroacoustics Branch, AIAA Member AIAA.

${ }^{4}$ Senior Research Engineer, Aeronautical Systems Analysis Branch, Senior Member AIAA

${ }^{5}$ Senior Research Engineer, Flight Dynamics Branch, Associate Fellow AIAA.

${ }^{6}$ Senior Scientist, Analytical Services and Materials.
} 
To further develop the technical readiness level of the low noise HWB design, the HWB aircraft design methods were advanced under a NASA Research Announcement (NRA) award to a team led by The Boeing Company. The objectives $^{7}$ of the NRA were to (1) design a representative HWB capable of meeting the NASA N+2 noise goal of CUM 42 EPNdB below the aircraft noise certification requirements of part 36 of the United States Code of Federal Regulations Title $14^{8}$ (herein referred to FAR 36) Stage $4^{9}$ and $25 \%$ reduction in fuel burn relative to B737/767 technology; (2) improve ANOPP2 (NASA's Aircraft NOise Prediction Program2) and develop methods for propulsive noise shielding; (3) fabricate a scaled model of the proposed HWB for NASA to conduct acoustic and low-speed aerodynamic testing. The Boeing Company started with the Cambridge-MIT Institute Silent Aircraft Initiative SAX $-40^{3}$ configuration and developed a cargo freighter to represent the initial operational aircraft capability in the 2020 time frame. ${ }^{7}$

From that design (known as the N2A-EXTE) a full span, 5.8-percent scale-model was provided to NASA to perform both aerodynamic ${ }^{10}$ and aeroacoustic ${ }^{11,12}$ testing. The key objectives of those tests were to characterize the low speed aerodynamics and noise of the design, and provide data for use in assessing certification noise metrics with respect to the NASA noise goals.

In this paper, the full system noise assessment of the N2A-EXTE vehicle is reported. The vehicle is described and the flight profile details required to meet FAR 36 are defined. The process for using the vehicle description and flight profile to predict noise at ground observer locations is presented. As part of the process the source noise for each of the aircraft components is required. The source noise is obtained by scaling acoustic measurements of the model in combination with predictions. The noise assessment results are presented as a series of updated strategies from a defined baseline N2A-EXTE configuration. The effect of each noise reduction technology/configuration is evaluated at the component and system level and cumulative noise margins relative to Stage 4 are reported.

\section{Aircraft and Propulsion System}

\section{A. Aircraft Description and Performance}

An artist's rendition of a HWB vehicle known as the N2A-EXTE aircraft is shown in Fig. 1. Some key design characteristics and mission requirements are given in Table 1. The Boeing Company NRA provided a vehicle concept design that was predicted (using Boeing Integrated Vehicle and Design System (BVIDS) tool suite ${ }^{7}$ ) to simultaneously meet the goals of $42 \mathrm{EPNdB}$ and a $25 \%$ fuel burn reduction. The vehicle configuration combines the aerodynamic benefits of a flying wing design with acoustic benefits of significant engine noise shielding by locating the engines on the top surface of the airframe.

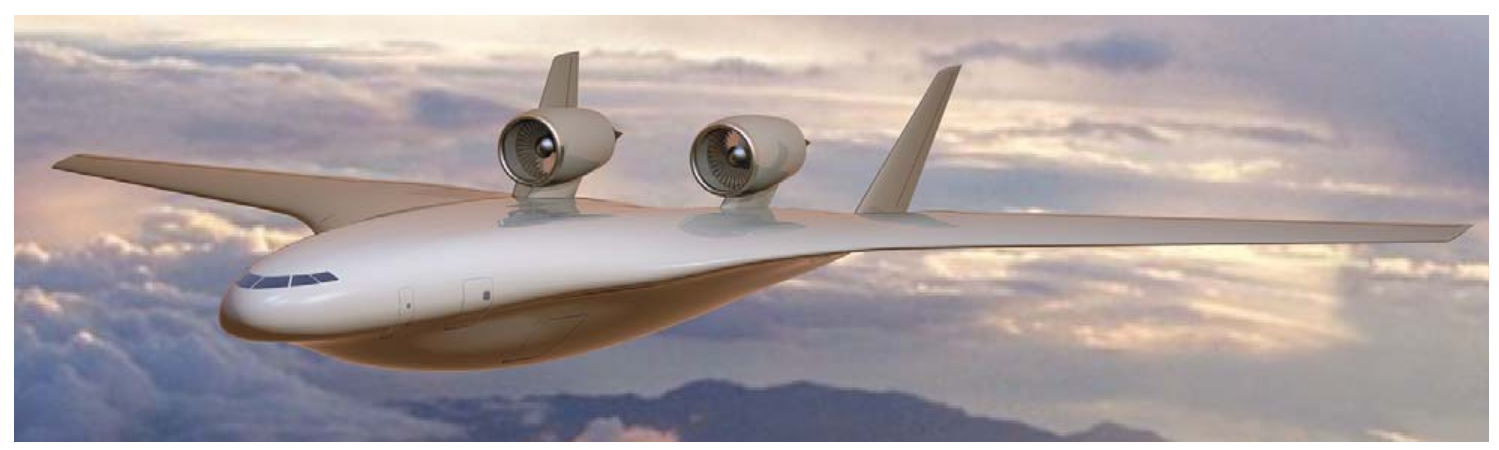

Figure 1. Artist rendering of the HWB N2A-EXTE aircraft concept designed by Boeing Research and Technology.

Although positioning the engines above the airframe and upstream of the trailing edge can provide significant noise shielding benefits, it can also greatly affect the aero-performance of the aircraft. Optimizing the acoustic benefit while providing a viable, albeit an aggressive aero-design, resulted in locating the two direct-drive turbofan engines 2.5D upstream of the trailing edge, where D is the fan exit diameter, as shown in Fig. 2. With this engine location, the airframe provides significant shielding of the aft-radiated engine sources (mainly the fan and jet with chevrons). The forward radiated engine sources (namely those associated with the fan) are even more shielded due to the larger extent of the airframe forward of the engines. The landing gear, not shown in Figs. 1 or 2, includes a 
nose and 2 main gear assemblies located on the underside of the airframe. The low noise technologies of the aircraft include a drooped leading edge, a specifically designed PAA (Propulsion Airframe Aeroacoustics) chevron nozzle set for increased shielding effectiveness ${ }^{13}$ and vertical tail designs and orientations to benefit performance as well as acoustics. The 11 trailing edge elevons shown in Fig. 2 serve to provide directional stability control as well as a positive pitching moment for takeoff when the center elevon is deflected up. ${ }^{10}$ Further details of the aeroperformance design and of the measured data of the low-speed aerodynamic directional stability characteristics can be found in References 7 and 10, respectively.

Table 1. N2A-EXTE design parameters and mission requirements

\begin{tabular}{|c|c|}
\hline Weight-takeoff (lbs) & 470,632 \\
\hline Weight-landing (lbs) & 343,462 \\
\hline Wing Span (ft) & 213.2 \\
\hline Max Fuel (lbs) & 128,600 \\
\hline Initial Cruise Altitude (ft) & 38,739 \\
\hline Initial Cruise Mach & 0.810 \\
\hline Initial Cruise L/D & 21.42 \\
\hline Initial Cruise SFC & 0.503 \\
\hline Final Cruise Altitude (ft) & 44,633 \\
\hline Final Cruise Mach & 0.810 \\
\hline Final Cruise L/D & 20.93 \\
\hline Final Cruise SFC & 0.505 \\
\hline Engine Bypass Ratio & 10 \\
\hline Engine Fan Pressure Ratio & 1.6 \\
\hline Static Sea Level Thrust (lb) & 69,757 \\
\hline Payload (lbs) & 103,000 \\
\hline Range (nm) & 6,000 \\
\hline All Engine Field Length (ft) & 5,828 \\
\hline
\end{tabular}

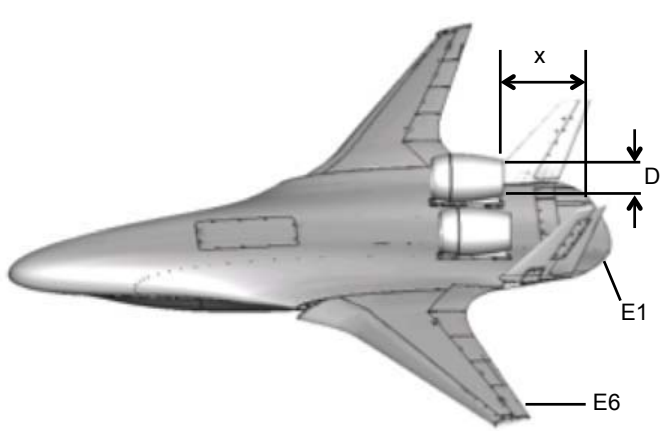

Figure 2. N2A-EXTE wind tunnel test model with engine nacelles located at $x / D=2.5$, baseline vertical tail design in aft position, drooped LE deployed, and elevons E1 to E6 are un-deflected.

\section{B. Engines description}

The NASA Glenn Research Center Engine Systems Analysis group used the Numerical Propulsion Simulation System ${ }^{14}$ (NPSS) to develop a engine model for the N2A-EXTE vehicle that would be viable for the 2020 IOC (Initial Operating Configuration) time frame and meet propulsion system requirements defined by

Boeing. ${ }^{7}$ The resulting design is a direct-drive turbofan engine with a fan pressure ratio (FPR) of 1.6, a bypass ratio 10 cycle, and is sized to produce a sea level static thrust of $69,757 \mathrm{lbs}$. (per engine). A schematic of the engine flowpath is shown in Fig. 3. Additional details of the design can be found in Reference 7.

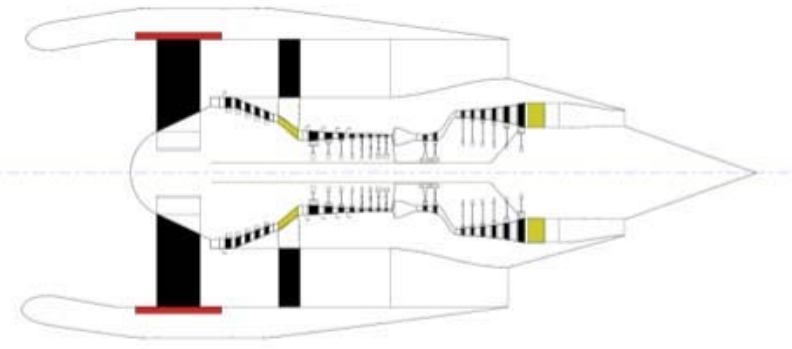

Figure 3. Schematic of the N2A-EXTE direct-drive turbofan engine model from NPSS. 


\section{System Noise Assessment Process}

\section{A. Process Overview}

An outline of steps and information required to predict aircraft system noise is shown in Fig. 4. The aircraft geometry and aero-performance definition are required to determine the details of the aircraft flight path (aircraft configuration and engine operating state along the flight trajectory) in accordance with the FAR 36 regulations. Once the flight path and aircraft operating state is known the aircraft source noise and installation effects can then be defined and the noise at far-field observer locations determined. For this present study, the far-field observer locations are the specific FAR 36 measurement locations, which are defined in the next section. In general, the aircraft source noise and installation effects are defined either from prediction, measurement, or both. The source noise along the flight path is then propagated through the atmosphere to observers, accounting for the effect of the ground. The time dependent and integrated noise metrics, such as Tone-corrected Perceived Noise Levels (PNLT) and Effective Perceived Noise Levels (EPNL) may then be computed.

Following the general steps outlined in Fig. 4, the specific

Aircraft geometry and aeroperformance definition

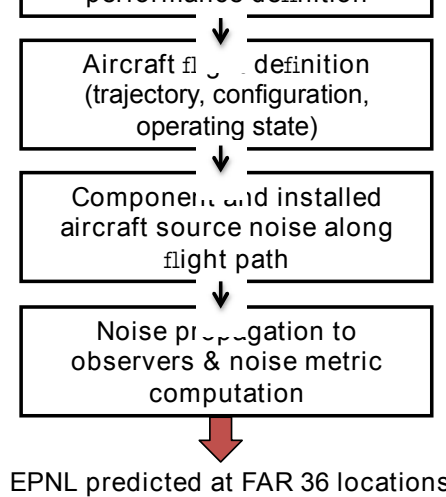

EPNL predicted at FAR 36 locations

Figure 4. Outline of aircraft noise prediction. noise prediction process for analyzing the N2A-EXTE vehicle was developed and is shown in Fig. 5. The low speed aeroperformance data obtained during the aerodynamic testing of the scale model is used in defining the flight profiles. The flight profile definition includes not only the aircraft path, but also engine operating conditions and aircraft configurations (deployment of elevons, landing gear, etc.) along the flight path. The engine states, flight profiles, and measured noise are input to NASA's multi-fidelity aeroacoustic framework Aircraft NOise Prediction Program $2^{15}$ (ANOPP2). The ANOPP2 framework provides capabilities to apply flight effects to the input measured source noise (which includes installation effects), combine those measurements with prediction, propagate to the far-field, and compute noise metrics. For this study, ANOPP2 employs the Aircraft NOise Prediction Program ANOPP ${ }^{16}$ for predicting the isolated and, subsequently, installed core and fan noise components. The isolated core noise is computed using the ANOPP GECOR noise module, which is based on the original developments of Emmerling ${ }^{17}$ and later adopted by the SAE A-21 Committee $^{18}$ with modifications. The isolated fan inlet and exit noise are computed using the ANOPP Heidmann ${ }^{19}$ fan module model with modifications for modern wide chord fan designs developed by Krejsa. ${ }^{20}$ The installed core and fan noise is computed by invoking the ANOPP module GENSUP ${ }^{16}$ which modifies the isolated source noise with measured suppressions to account for installation effects. This is the same procedure outlined in Reference 13, whereby noise suppressions in terms of $\Delta \mathrm{dB}=$ SPLshielded - SPLunshielded were determined from measurement and applied to the engine sources. In the present paper, the noise suppressions are determined from the aeroacoustic testing. The measured (jet and airframe) and predicted (fan and core) installed source noise components are propagated to far-field observers using the ANOPP module PRO $^{16}$. The desired noise metrics are then computed.

In order to utilize the measured noise results from the aeroacoustic test, the data required processing to prepare for input to ANOPP2 and subsequently ANOPP. For propagation to ground observers, ANOPP requires that the source noise be represented as: 1/3-octave band spectra defined from $50 \mathrm{~Hz}$ to $10 \mathrm{kHz}$ without atmospheric attenuation (i.e. lossless) specified at source or emission coordinates, including flight effects (such as Doppler and convective amplification) and be defined over a large range of polar $(\theta)$ and azimuthal $(\phi)$ directivity angles. Noise defined in this manner is often called a "source noise hemisphere". Hence, the processing of the acoustic wind tunnel test data required several steps to convert from the wind tunnel noise measurements to lossless, full-scale noise results appropriate for use in the aircraft system noise prediction process. The details of these steps are given in section IV of this paper. 


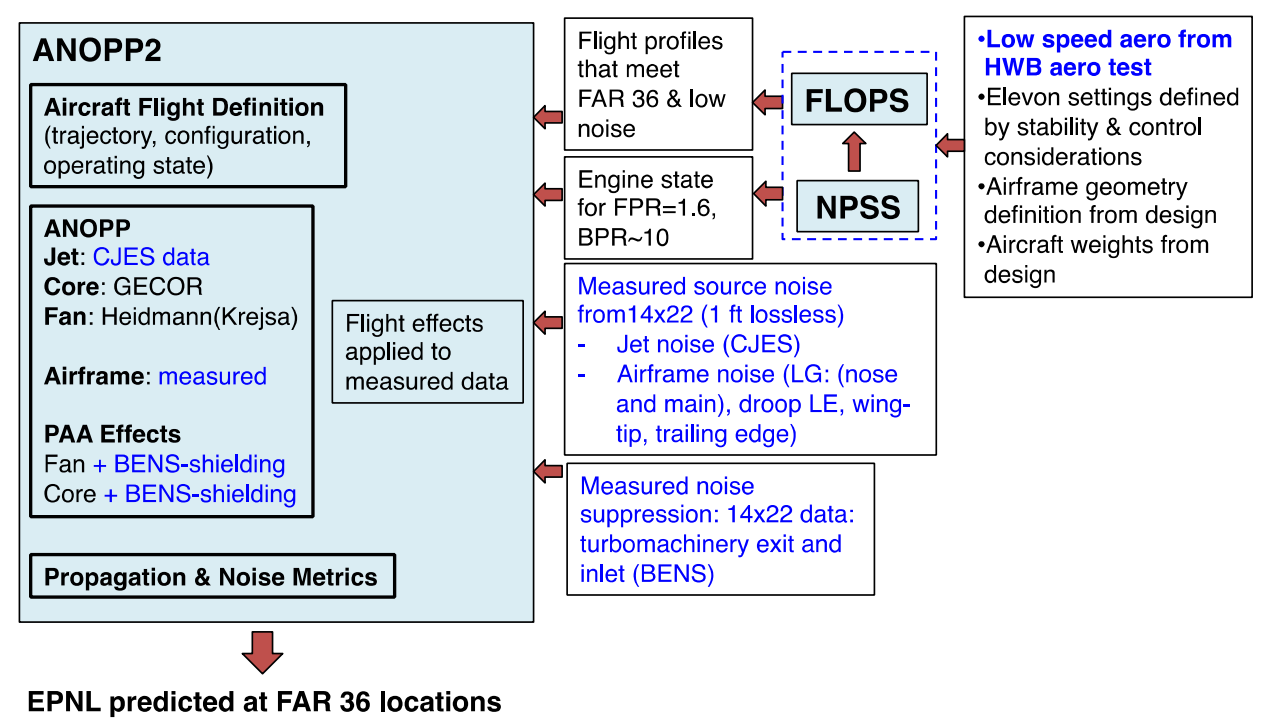

Figure 5. System noise prediction process (measured data identified in blue text).

\section{B. Aircraft Flight Profile Definition}

Flight operational conditions play an important role in aircraft system noise assessments. The certification flight procedures as defined by the FAR 36 Stage 3 regulations $^{8,9}$ were followed to determine the flight profiles (aircraft operating conditions and trajectories) for approach and takeoff of the N2A-EXTE aircraft. The flight trajectories and conditions were developed using the FLight OPtimization System ${ }^{23}$ (FLOPS) analysis code that was updated to address features of HWB configurations. ${ }^{24}$ Measured aerodynamic characteristics in terms of the lift, drag and pitching moment ${ }^{10}$ were used as input to FLOPS. Directional stability control considerations guided the deployment schedule of the eleven independently deflectable elevons along the trailing edge of the vehicle. Referring to Fig. 2, E1 is the center elevon positioned between the 2 vertical tails and E2-E6 are the five elevons extending across the trailing edge of each wing. The outer two elevons (E5 and E6) on each wing remain stowed ( $0^{\circ}$ deployment angle) for all the flight conditions considered, while elevons E1-E4 are deployed for specific conditions. When deployed, the elevons are deflected "up" (i.e. at negative angles, towards the engines). The high-lift drooped leading edge is deployed the same for both the approach and takeoff configurations. In these configurations, the drooped deployment angle varies along the span from 20 degrees at the most inboard section to 30 degrees near the wing tip. ${ }^{7}$ A summary of the key certification flight profile parameters predicted by FLOPS is given in Table 2. The two approach flight conditions A1 and A2, (given in Table 2 and mainly differing in approach speed), were developed to investigate the potential noise benefit of reducing speed. The approach A1 has a significantly lower speed than approach A2, intended to reduce airframe noise. The difference in noise for these flight conditions and impact on the overall metrics is presented in the section VI.

The engine state definition was predicted using the Numerical Propulsion System Simulation ${ }^{14}$ (NPSS) engine model that was developed at the NASA Glenn Research Center. The engine state parameters were defined for the range of Mach numbers, throttle settings, and altitudes required to fully cover the conditions encountered during the approach and takeoff flight paths. This database of engine states is used in the FLOPS analysis to determine aircraft thrust, drag, and moments along the flight path, and in the ANOPP noise models for the fan and core source noise predictions.

Figure 6 illustrates the FAR 36 procedure and the location of the certification reference locations, known as sideline (SL), approach (AP) and flyover (or cutback (CB)). The EPNL levels determined at the three certification points are summed to obtain the CUM EPNL metric. On approach, the aircraft must fly on a three-degree descent slope at a constant speed with landing gear and high-lift systems deployed. On takeoff, the aircraft must climb at full engine power to an altitude of at least 985 feet, where a noise abatement cutback maneuver may be executed. For both the takeoff and landing procedures, the aircraft must be at its maximum certified weight. 
Table 2: N2A-EXTE noise certification flight conditions.

\begin{tabular}{|c|c|c|c|c||}
\hline & $\begin{array}{c}\text { APPROACH } \\
\text { A1 }\end{array}$ & $\begin{array}{c}\text { APPROACH } \\
\text { A2 }\end{array}$ & $\begin{array}{c}\text { TAKEOFF } \\
\text { (SIDELINE) }\end{array}$ & $\begin{array}{c}\text { CUTBACK } \\
\text { (FLYOVER) }\end{array}$ \\
\hline Weight (lbs.) & 343462 & 343462 & 470632 & 470257 \\
\hline Altitude (ft.) & 394 & 394 & 982 & 2392 \\
\hline Speed (kts) & 125.4 & 139.9 & 156.2 & 156.2 \\
\hline $\begin{array}{c}\text { Est. Mach \# } \\
\text { (a=1120ft/s) }\end{array}$ & 0.19 & 0.21 & 0.23 & 0.23 \\
\hline AOA (deg) & 12.1 & 13.9 & 11.9 & 12.7 \\
\hline Climb Angle (deg) & -3.0 & -3.0 & 9.2 & 5.1 \\
\hline $\begin{array}{c}\text { Elevon Angles per } \\
\text { wing }\end{array}$ & E1-E6 at 0 deg & $\begin{array}{c}\text { E1-E4 at -10 deg } \\
\text { E5-E6 at 0 deg }\end{array}$ & $\begin{array}{c}\text { E1 at -10 deg } \\
\text { E2-E6 at 0 deg }\end{array}$ & $\begin{array}{c}\text { E1 at -10 deg } \\
\text { E2-E6 at 0 deg }\end{array}$ \\
\hline Thrust (lbs.) & 10950 & 14842 & 107670 & 75770 \\
\hline \% max Thrust & 10.2 & 13.8 & 100.0 & 70.4 \\
\hline
\end{tabular}

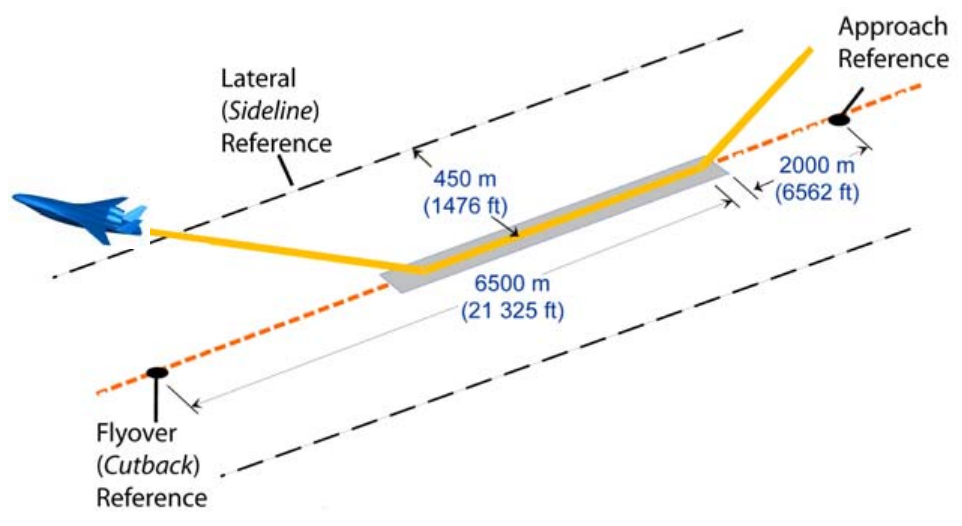

Figure 6. FAR 36 noise certification reference locations.

Figure 7 shows the aircraft speed, Thrust/Thrust ${ }_{\text {MAX }}$, AOA (angle-of-attack) and altitude as a function of ground distance for both the approach and takeoff profiles. The normalizing factor Thrust ${ }_{\mathrm{MAX}}$, is the maximum thrust at the flight condition (approach, takeoff, or cutback) Mach number for sea level altitude. The aircraft configurations for A1 and A2 approach conditions have differing elevon settings. For approach A1, all elevons are stowed (i.e. set at $0^{\circ}$ deployment angle). For A2, elevons E1-E4 are set at $-10^{\circ}$ deployment angle and E5 remains stowed. The altitude profile is the same for both approaches, since both are on a three-degree glide slope. The takeoff profiles shown in Fig. 7 combine the segments for sideline and cutback, which are identified in the altitude profile plot. To be consistent with previous HWB noise assessment studies ${ }^{2,3,6}$, the sideline reference location was set when the vehicle was at $1000 \mathrm{ft}$. altitude. During the flight segment over the flyover reference point the engines were cutback to about $72 \%$ of the available thrust, and the aircraft was at an altitude of about $2390 \mathrm{ft}$. For the noise computation, the sideline and cutback segments were flown separately to be consistent with the computations performed in the previous published studies. 

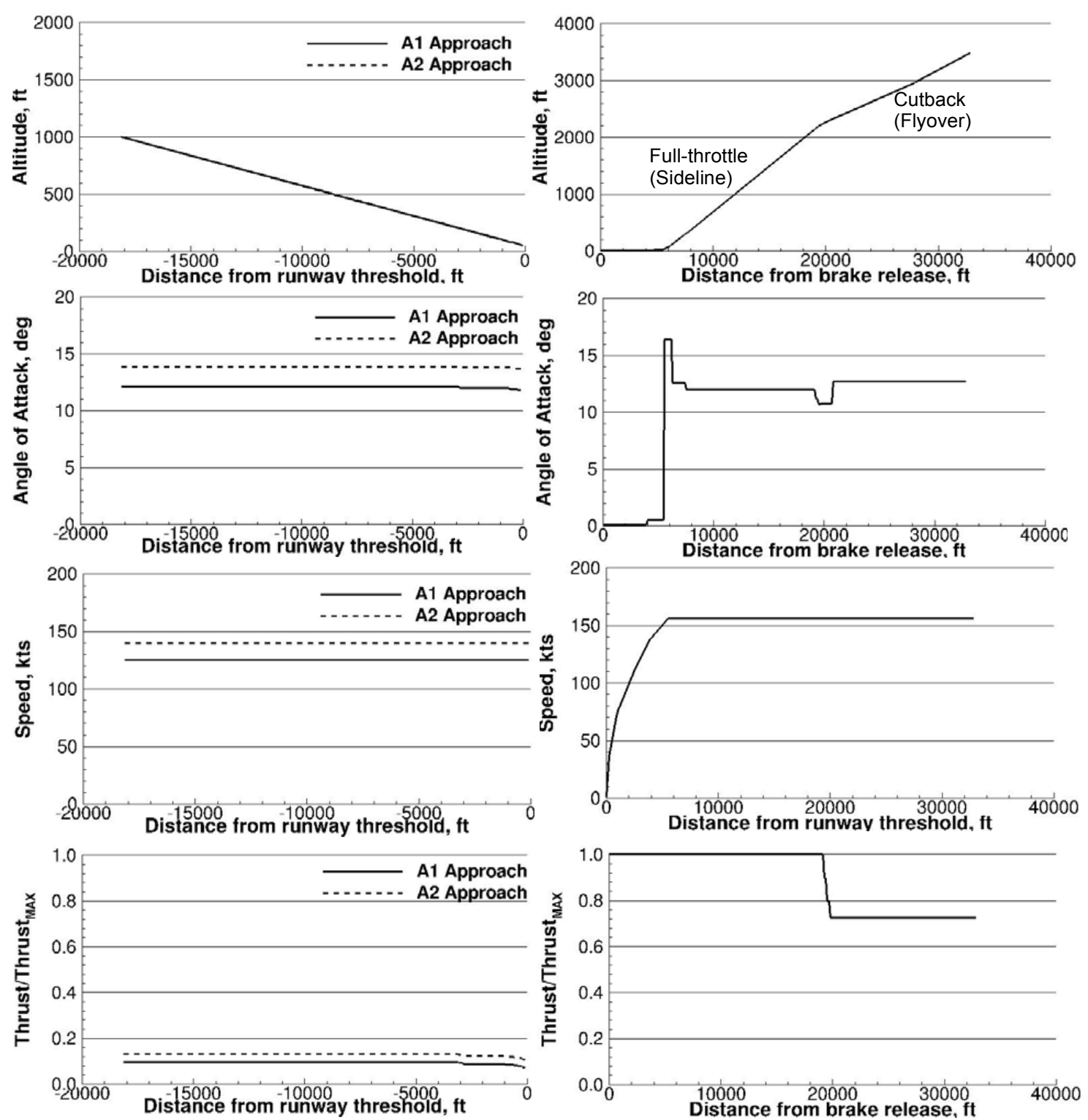

Figure 7. Approach and takeoff flight condition profiles.

\section{Acoustic Data Processing and Noise Scaling}

As mentioned earlier, the measured noise results used in this study are from the aeroacoustic testing ${ }^{11}$ of a $5.8 \%$ scale-model of the HWB aircraft. The aeroacoustic test was conducted in the $14 \times 22$ Foot Subsonic Tunnel at NASA Langley Research Center. The tunnel is a closed-circuit, single return wind tunnel that can be configured with a closed or open test section. The open test section configuration was used during aeroacoustic testing with acoustic treatment on the floor, walls, ceiling, and model test stand. A picture of the test set-up is shown in Fig. 8, with the model mounted inverted to allow flyover measurements by the ceiling mounted phased array and the tower/truss 
microphone traverse systems. The tower/truss microphone traverse systems, which were located outside the wind tunnel shear layer, consisted of 29 microphones of 0.125 " diameter, spaced at approximately 7.5 degrees increments in azimuthal directivity relative to the model. A large portion of combined polar and azimuthal noise directivity under the aircraft model was obtained by traversing the tower/truss microphones systems to different streamwise positions. In addition to the tower/truss microphone system, a two-dimensional phased array system consisting of 97 pressure field microphones of 0.25 " diameter was used to locate the different noise sources on the HWB and determine their respective contribution to the overall noise. The Deconvolution Approach for the Mapping of Acoustic Sources $^{25}$ (DAMAS) was used to process the phased array data. The phased array moved in concert with the tower/truss system and was positioned in the same plane as the truss microphones (as shown in Fig. 8). Complete details of the test set-up, measurement and data acquisition systems can be found in References 21, 22 and 26-28.

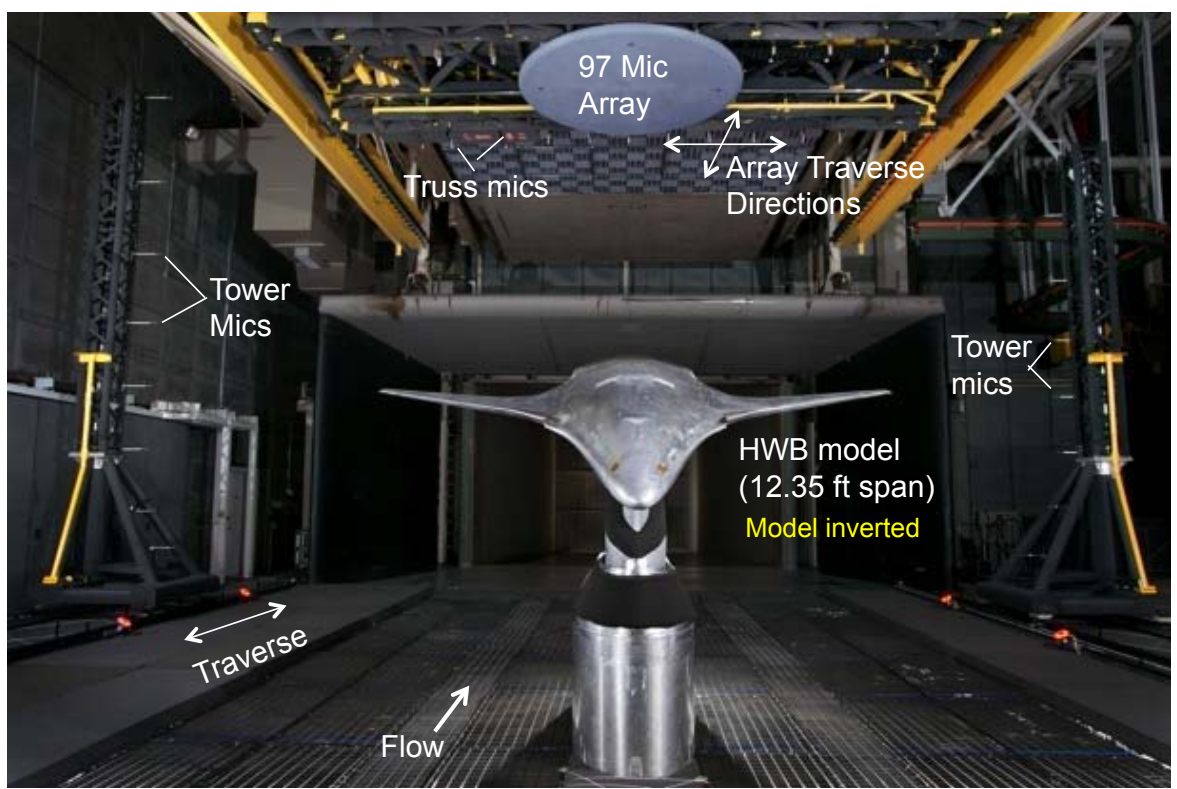

Figure 8. Geometrically scaled-model of N2A-EXTE HWB aircraft shown in 14x22 Tunnel test section with microphone phased array and tower/truss microphone instrumentation.

The test was conducted in three parts. The first focused on characterizing shielding by the HWB airframe of inlet and aft radiated broadband noise based on engine placement and variations in vertical tail configurations. ${ }^{21}$ The broadband engine noise component was simulated using two Broadband Engine Noise Simulators (BENS) ${ }^{21}$. Shielding of the inlet and exhaust radiated noise was measured separately by capping, respectively, the exhaust or inlet of the BENS nacelles. Details on this portion of the test and key results of the exhaust side are provided in Reference 21. In the present paper, the BENS acoustic data are used to create noise suppression maps that are then applied to predicted fan and core source noise components to provide representative installed fan and core radiated noise for the N2A-EXTE aircraft.

The second part of the test focused on characterization of the airframe noise sources of the full aircraft configurations for each certification flight profile, as well as for airframe configuration variations to investigate the effects of elevon settings, drooped leading edge deployment, vertical tail configurations and landing gear deployment. Unlike the BENS data, the airframe noise measurement levels are processed and scaled for direct input to the system noise prediction process.

The third part of the test focused on characterizing shielding of the jet noise based on engine placement, vertical tail configuration and jet exit nozzle designs (with and without chevrons). The jet noise was accurately simulated through the use of two compact jet engine simulators, known as Compact Jet Engine Simulators (CJES). The two CJES units were designed to represent a 5.8\% scale model of the jet cycles of a dual-stream hot jet defined by the NPSS model of the direct-drive turbofan engine, previously described. The details of the CJES design and key noise results from this third part of the test are provided in Reference 22. Similar to the airframe noise, the jet noise measurement levels are processed and scaled for direct input to the system noise prediction process. 
In order to utilize the model-scale acoustic measurements for aircraft noise prediction, the data must be properly scaled and made compatible for input to the prediction process. As mentioned earlier, the noise prediction process requires that the component source noise be defined as lossless noise levels over a 'complete' 1 foot hemisphere ("source noise hemisphere"), where 'complete' means that noise is defined for the full extent of polar and azimuthal directivity angles and frequency range required to compute the noise metrics at each of the certification measurement points. In addition the source noise hemispheres must be defined in emission coordinates and include flight effects that account for Doppler frequency shift between measured and desired Mach numbers, as well as atmospheric source strength corrections to account for the difference in measurement ambient atmosphere relative to international standard atmosphere (ISA) for which the aircraft noise assessment is performed. The data from the three test parts required similar processing steps but differ in details depending on the source. Figure 9 outlines the basic sequential steps required to process the measured data.

The BENS data will be used to illustrate and describe each step of the processing. The first step represents

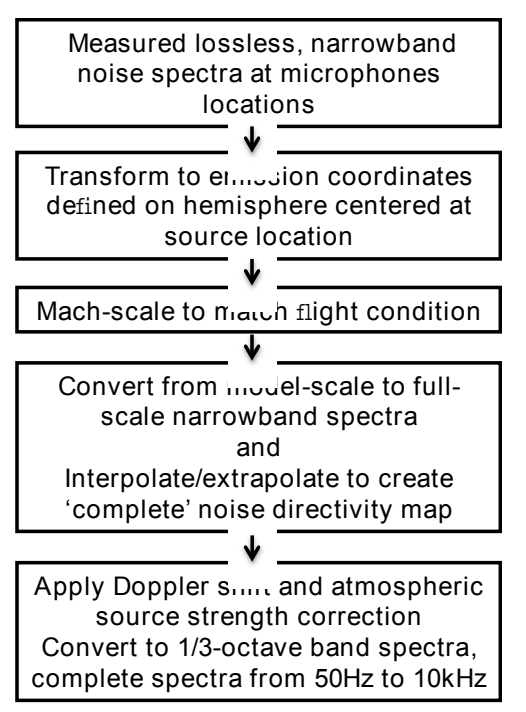

Figure 9. Acoustic data processing steps. processing of the raw noise data into lossless (removal of atmospheric effects between microphone and a specific source location) narrowband noise spectra accounting for shear layer effects, microphone directional effects and removal of tunnel background noise ${ }^{26,27,28}$. The result of this processing is shown in Fig. 10a. The HWB model is shown inverted in the test section with noise directivity measurements in terms of Sound Pressure Level (SPL) (shown for the narrowband $f_{n b}=31.5 \mathrm{kHz}, \Delta f_{n b}=30.5 \mathrm{~Hz}$ ) obtained from traversing the tower/truss microphone system. The microphones are indicated by the black dots. Figure 10b shows the same data propagated to a $15 \mathrm{ft}$. model-scale hemisphere with its center located at the Starboard-BENS (S-BENS) exit (result from the second box of Fig. 9). The atmospheric effects have been removed and the values have been adjusted for spherical spreading to the $15 \mathrm{ft}$ radius. (For convenience of illustration a $15 \mathrm{ft}$. radius is chosen to allow for both model and data to easily fit on the figure together. The final result for input to ANOPP2 is on a full-scale hemisphere of radius $1 \mathrm{ft}$.) Processing the data in this manner assumes that the measured data were obtained in the acoustic far-field. To account for two BENS sources, the starboard BENS data are mirrored about $\phi=0^{\circ}$ to create a representative port side BENS data set. The two data sets are then summed on a pressure-squared basis to obtain the total noise field. This process assumes that the interaction effects of two BENS operating is minimal and that the difference in distance between BENS source locations is negligible compared to the far-field distance for which the data will be used. The error associated with the latter assumption was quantified to be on the order of less than $0.25 \mathrm{~dB}$ spectrally. ${ }^{22}$ Not all (BENS, airframe or jet noise) data were obtained at the correct flight Mach number, engine thrust setting an/or angle-of-attack indicated in Table 2. Thus, additional scaling and adjustments to the measured noise levels were developed and applied (third box of Fig. 9). The required scaling and adjustments will be described subsequently.

The next step (fourth box of Fig. 9) is to create full-scale, 'complete' polar/azimuthal directivity maps that include data from $\theta=\left[0^{\circ}, 180^{\circ}\right], \phi=\left[-90^{\circ}, 90^{\circ}\right]$, at increments of $\Delta \theta=\Delta \phi=10^{\circ}$. The full-scale spectral results are obtained by scaling the frequencies of the model-scale noise data and their amplitudes per Strouhal scaling law presented by Brooks in Reference 29. The scale factor between model and full-scale is SF (model-scale/full-scale= $\mathrm{SF}=0.058)$. The full-scale frequencies and narrowband amplitudes for a given distance $\left(\mathrm{R}_{m s}\right)$ are obtained as follows:

$$
\begin{gathered}
0_{0}={ }_{0} * \mathrm{SF} \\
\Delta 0_{0}=\Delta \quad 0 * \mathrm{SF} \\
\mathrm{SPL}_{0}=\mathrm{SPL}_{0}+20 \log 10 \$ \frac{\mathrm{R}_{0} / \mathrm{SF}_{0}}{\mathrm{R}_{0}}
\end{gathered}
$$

where subscripts $f s$ denotes full-scale, $m s$ denotes model-scale, and $\mathrm{R}$ is the distance from source to observer. 


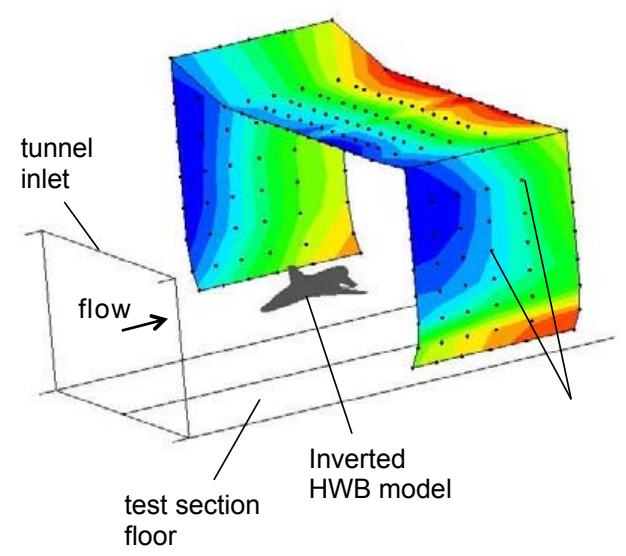

a) Measured SPL over area traversed by microphones (shown as black dots)

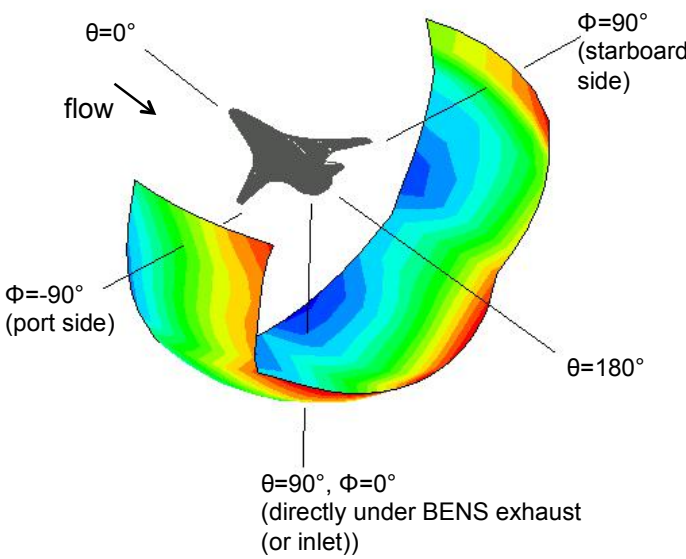

b) Transformed SPL to hemisphere $\left(R_{\mathrm{ms}}=15 \mathrm{ft}\right)$ centered at the BENS exit

Figure 10. Measured model-scale SPL contours from starboard BENS located at $X / D=2.5$, narrowband $f_{\mathrm{ms}}=31.5 \mathrm{kHz}, \Delta f_{\mathrm{ms}}=30.5 \mathrm{~Hz}$, (A1 approach condition).

The creation of a 'complete' directivity map is accomplished through the use of a bivariate interpolation algorithm $^{6}$ for irregularly spaced data, which allows for both interpolation and extrapolation. The result is shown in Fig. 11a. The small black dots and their surrounding boundary on Fig. 11a indicate the projection of microphone

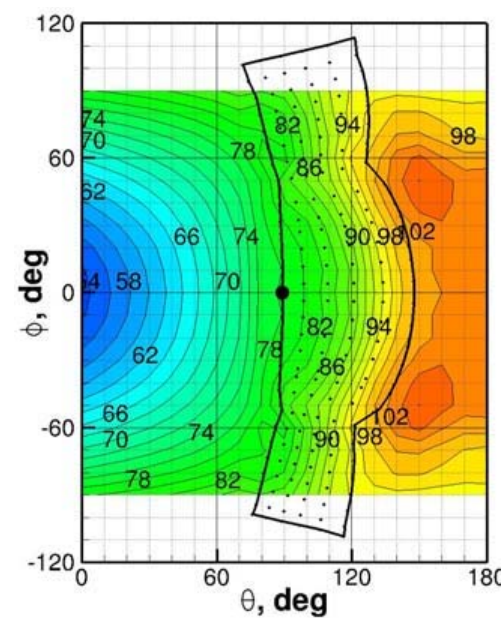

a) BENS at $X / D=2.5$

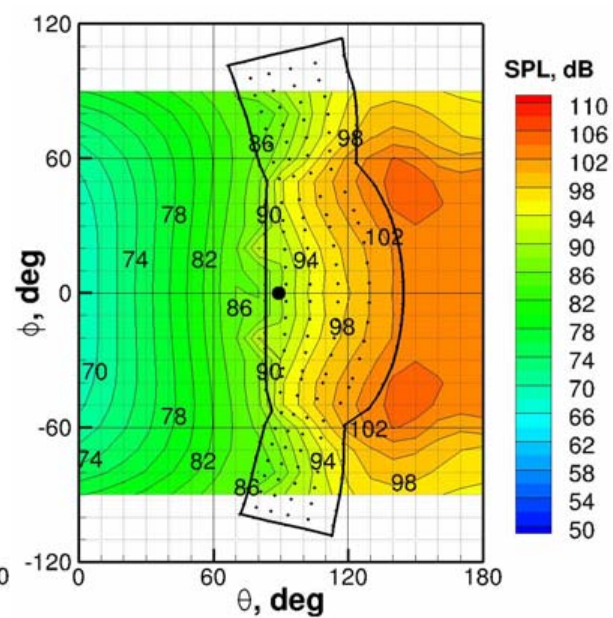

b) BENS at $\mathrm{X} / \mathrm{D}=-0.5$

Figure 11. Full-scale noise maps representing both BENS sources over complete range of polar and azimuthal directivity angles, narrowband $f_{\mathrm{fs}}=1827 \mathrm{~Hz}, \Delta f_{\mathrm{fs}}=1.77$ Hz. $\left(R_{\mathrm{fs}}=15 \mathrm{ft}\right.$.), (A1 approach condition).

locations to the hemisphere as these are the only locations of measured data. The large black dot located at the center of the hemisphere $\left(\theta=90^{\circ}, \phi=0^{\circ}\right)$ is the BENS source location. To check the interpolation, interpolated levels determined at the measurement locations were found to equal the measured levels, which provided some confidence in the data fit. The validity of the extrapolated levels (outside of the measured data boundary) was more difficult to assess and relied heavily on expected trends. It should be noted that the approach and cutback conditions only requires polar directivity data for $\phi=0^{\circ}$, while the sideline condition requires directivity data for both polar and 
azimuthal angle ranges. However, to ensure robustness and confidence in the final EPNL levels, the full directivity for each noise source is examined and evaluated for expected trends, particularly at the noise directivity angles that are most important for the noise assessment. The data in Fig. 11b are BENS data processed in the same manner but for a configuration where the BENS are located 0.5D downstream of the HWB trailing edge $(\mathrm{X} / \mathrm{D}=-0.5)$.

In the last step of Fig. 9, the Doppler frequency shift and ambient source strength correction are applied to the full-scale narrowband spectra. The ambient source strength relative to the ISA conditions is

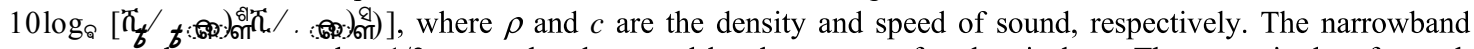
spectra are then converted to $1 / 3$-octave band spectral levels on a one-foot hemisphere. The acoustic data for each noise type could only be obtained over a subset of the $1 / 3$-octave frequency range $(50 \mathrm{~Hz}$ to $10 \mathrm{kHz})$ required by the system noise process. The useable narrowband model-scale frequency range depended on the noise source being measured, run condition, and microphone measurement location. Low frequency limits were typically dictated by background noise contamination, and upper frequency limits were typically determined based on microphone frequency response characteristics. The measured spectra were extended to include spectral levels for the full range of frequencies from $50 \mathrm{~Hz}$ to $10 \mathrm{kHz}$ depending on noise source, and hence these details are provided in the associated sections entitled BENS suppression, Airframe noise, and CJES: Jet noise.

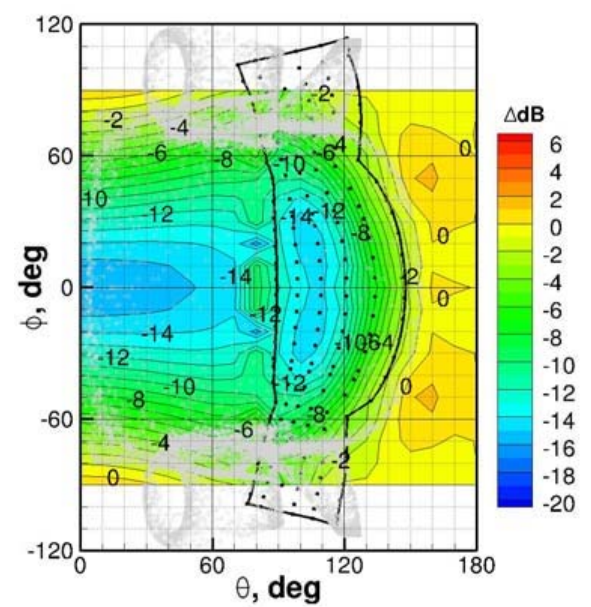
of polar and azimuthal directivity angles, 1/3-octave $f_{\mathrm{fs}}=2 \quad \mathrm{kHz} . \quad\left(R_{\mathrm{fs}}=15 \quad \mathrm{ft}\right), \quad$ A1 approach condition.
Figure 12. Noise suppression map representing both BENS sources over range

\section{A. BENS suppression}

The BENS data are further processed to obtain $\Delta \mathrm{dB}$ levels (suppression level maps), which are computed by subtracting on a $\mathrm{dB}$ basis the isolated (unshielded) BENS noise measured when the BENS are located at $X / D=-0.5$, (example shown in Fig. 11b) from the shielded BENS noise measured when the BENS are located at $\mathrm{X} / \mathrm{D}=2.5$, (example shown in Fig 11a). The BENS inlet suppression are similarly computed using unshielded inlet source data (obtained in an alternate anechoic facility previous to the acoustic test) and the shielded inlet source data when the BENS are located at $\mathrm{X} / \mathrm{D}=2.5$. Negative $\Delta \mathrm{dB}$ levels indicate noise suppression and positive values indicate noise increase. The suppression map created using the data of Fig. 11 is shown in Fig. 12. The black outline and dots are the same as before and indicate the location of measured data. The light grey dots (ghost image) on the maps are projections of the HWB body outline points onto the hemisphere with respect to a source located between the BENS's exit centers. As expected, significant noise reduction is seen for regions where the projection of the HWB body is present and minimum to no noise reduction is seen for regions outside the HWB projection. It should be noted that the measured data extent (black dots and outline) shown in Fig. 11 did not capture the transition between shielded and unshielded regions, however other data from the test did capture this transition ${ }^{21}$. The extrapolated data in both Fig. 11 and 12 are consistent with the analysis of the other test points and do exhibit the expected shielding trends observed in both Figs. 11 and 12.

In Fig. 13, 1/3-octave suppression spectra for a range of polar angles along the flight path $\left(\phi=0^{\circ}\right)$ are shown for the A1 approach condition. As expected the largest suppression is seen for polar angles under the vehicle $\left(\theta=70^{\circ}\right)$ and suppression levels decrease to nearly zero at larger angles for which the observer is in line of sight of the source. As noted earlier, the BENS data are not available over the entirety of the required frequency range. To complete the $1 / 3$-octave suppression $(\Delta \mathrm{dB})$ spectra from $f_{\mathrm{fs}}=50 \mathrm{~Hz}$ to $10 \mathrm{kHz}$, the suppression value at the lower limit of the available frequency range is used for frequencies down to $50 \mathrm{~Hz}$. Similarly, the suppression value obtained at the upper limit of available frequency range is used for frequencies up to $10 \mathrm{kHz}$. It is expected that the suppression at the higher frequencies is likely to be larger than that assumed using the last available suppression value at $4 \mathrm{kHz}$ (as indicated by the data trends shown) hence, this approach is considered to provide a conservative estimate. Conversely, the suppression levels at the lower frequencies are probably less than indicated, however noise at these frequencies is further attenuated due to the noy weighting employed as part of determining the EPNL metric ${ }^{8,16}$. 


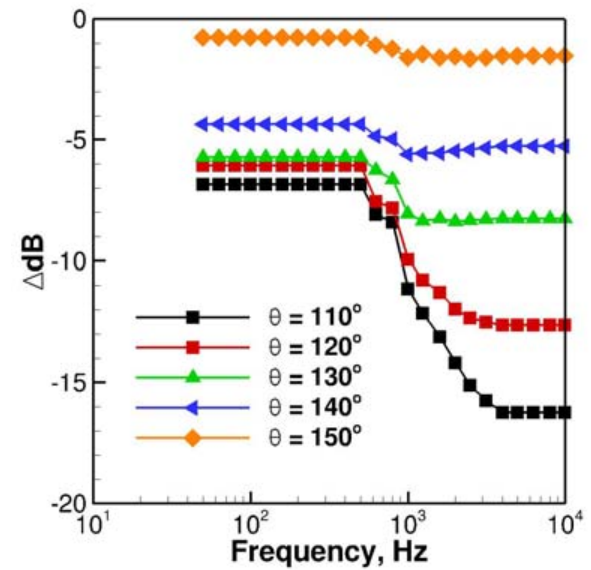

Figure 13. BENS exit suppression as a function of full-scale frequency at $\phi=0^{\circ}$ for different polar angles, $\mathrm{A} 1$ approach condition.

\section{B. Airframe noise}

Airframe noise measurements were obtained using the tower/truss microphone system to define the total airframe noise directivity and the DAMAS processed phased-array measurements to provide airframe component spectra. For the approach conditions, the main airframe sources included the nose and main gear, the side-edges (inboard and outboard) of the drooped leading edge, trailing edge noise on the airframe and vertical tails, and contributions from deployed elevons. The airframe component noise spectra obtained from the phased array are shown in Fig. 14 for the A2 approach condition at an observer located almost directly beneath the aircraft $\left(\theta=73.5^{\circ}\right.$, $\phi=0^{\circ}$ ). The relative ranking of the key airframe noise components is indicated. Note that, although the trailing edge noise was not separated from the total airframe noise, it is nevertheless a contributor to the overall airframe noise. The port and starboard main landing gear are shown as separate sources and are nearly identical in spectral shape and level for this observer location. A similar trend is seen for the port and starboard drooped LE side-edges (inboard and outboard). As expected, the landing gear (when deployed) is the dominant airframe noise source. When the landing gear is not deployed, trailing edge noise and the side-edges on the drooped leading edge are the main contributors to the overall airframe noise component.

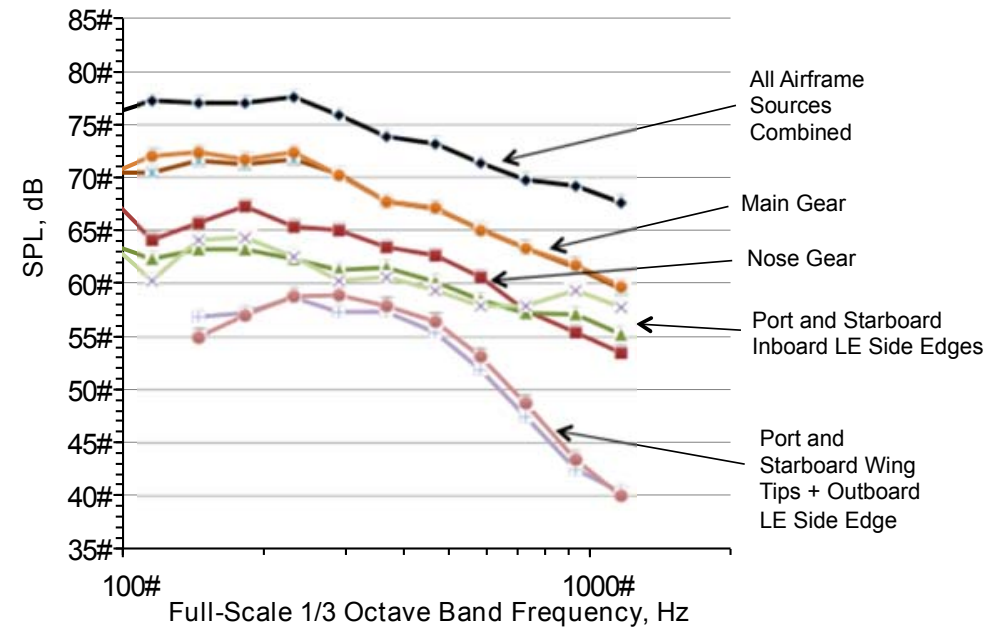

Figure 14. Noise ranking of airframe sources, 1/3-octave full-scale spectra

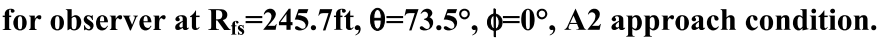

The airframe noise directivity data (from traversing the tower/truss system) were obtained for the approach conditions but not for the sideline (SL) and cutback (CB) conditions. The noise data for the A1 configuration obtained at $\mathrm{M}=0.17$ without the landing gear is scaled to represent airframe noise for SL and $\mathrm{CB}$ conditions. The change in emission coordinates for the angle-of-attack difference between A1 and the CB and SL conditions was determined and used in place of those determined for the A1 condition. The sound pressure levels and frequency scaling to account for the Mach number change from $M=0.17$ to $M=0.235$ is performed using the following (Mach-

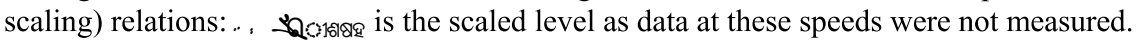

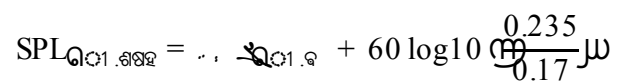




$$
\begin{aligned}
& \text { ெ1. .बध }=.01 .8 * \frac{0.235}{0.17} \mu \\
& \Delta \text { ெ1 .ावश }=\Delta \text { ता .ब } * \frac{0.235}{0.17} \mu
\end{aligned}
$$

The airframe noise directivity measurements were made over similar polar and azimuthal angles ranges as for the BENS data. For the airframe noise, the center of the source noise hemispheres is at a point centered between the two main gears. The full-scale $(2.0 \mathrm{kHz} \mathrm{1/3-octave} \mathrm{SPL)} \mathrm{airframe} \mathrm{noise} \mathrm{directivity} \mathrm{map} \mathrm{of} \mathrm{the} \mathrm{A2} \mathrm{condition} \mathrm{is} \mathrm{shown} \mathrm{in}$ Fig. 15. Again the black dots and outline indicate the measurement locations and region. Unlike for the BENS data,

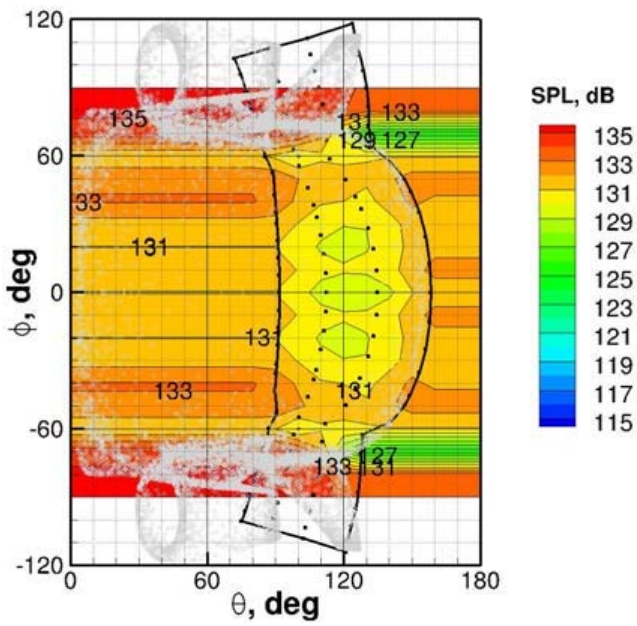

Figure 15. Airframe noise directivity map frequencies. Below $125 \mathrm{~Hz}$, the level at $125 \mathrm{~Hz}$ is used. representing airframe sources for A2 Above $3150 \mathrm{~Hz}$ to $10 \mathrm{kHz}$, the level at $3150 \mathrm{~Hz}$ is configuration on approach, 1/3-octave $f_{\mathrm{fs}}=\mathbf{2 . 0} \mathrm{kHz}$. decreased $1 \mathrm{~dB}$ per $1 / 3$-octave band to $10 \mathrm{kHz}$. The result $\left(\mathbf{R}_{\mathrm{fs}}=\mathbf{1 5} \mathrm{ft}\right)$. data region, the last value at the measured data region boundary is used, since the bivariate extrapolation for these data gave inconsistent trends.

In Fig. 16, 1/3-octave total airframe noise spectra for a range of polar angles $\left(\theta=\left[90^{\circ}, 150^{\circ}\right]\right)$, with azimuth angle of $\phi=0^{\circ}$ are shown for the A2 condition with (dashed lines) and without landing gear (solid lines). The A2 spectral levels that include landing gear are noticeably higher than those without landing gear over the measured frequency range $(125 \mathrm{~Hz}$ to $3150 \mathrm{~Hz})$. The increase in spectral levels around $1000 \mathrm{~Hz}$ for the data without landing gear is most likely due to the noise generated at the inboard side-edges of the port and starboard inboard drooped LE. As with the BENS data, the airframe noise data do not contain data for the full needed frequency range $(50 \mathrm{~Hz}$ to $10 \mathrm{kHz})$. To remedy this deficiency, extensions were defined to follow the expected spectral trends at both the high and low decreased $1 \mathrm{~dB}$ per $1 / 3$-octave band to 10
of these extensions can be seen in Fig. 16 to complete the noise directivity outside of the measured

\section{CJES: Jet noise}

Jet noise measurements were obtained for a limited range of engine cycles and jet configurations ${ }^{22}$. For the present study, only the jet noise data obtained when the engine nacelles are at $\mathrm{x} / \mathrm{D}=2.5$ with the optimized PAA chevrons installed are used. Even though multiple wind tunnel flow conditions were investigated for the cutback and sideline conditions during testing, the background noise levels for $\mathrm{M}=0.23$ cases were typically too high for accurate measurements at low frequencies. Thus, data taken at the $\mathrm{M}=0.17$ flow condition at specific setpoints are scaled, for use within the system noise assessment process. For the case of the takeoff (sideline) cycle point used in this analysis, a mismatch of desired and actual fan stream nozzle pressure ratio was discovered after testing, leading to a significantly lower noise level than expected. A correction of $4.55 \mathrm{~dB}$ was used to adjust the measured noise levels to create representative noise spectra for that condition as discussed in Reference 22.

Even though two CJES units were available during testing, only one was operated at a time for most of the test. Similar to the BENS processing, to account for 2 CJES sources, the starboard (or port) CJES data are mirrored about $\phi=0^{\circ}$ to create representative port (or

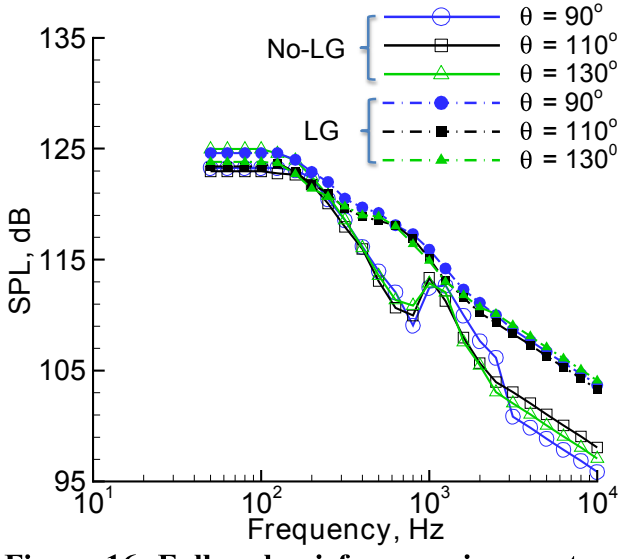

Figure 16. Full-scale airframe noise spectra with and without landing gear, A2 approach condition of $\mathrm{M}=\mathbf{0 . 1 9}, \phi=0^{\circ}$. 
starboard) side CJES data and then the two data sets are summed on a pressure-squared basis to obtain the total noise field. This process does not account for shielding and interaction effects between the two jet plumes and assumes that the difference in distance between CJES source locations is negligible compared to the far-field distance for which the data will be used. Evaluation of these effects were not available for inclusion in this study, but it is expected that the twin jets would exhibit an additional shielding benefit, particularly at the sideline location, and potential noise increased due to plume interaction at the flyover location ${ }^{33,34}$.

Figure 17a shows the directivity map (source noise hemisphere) at the full-scale frequency of $500 \mathrm{~Hz}$ for the cutback condition. The source noise hemisphere is on the midpoint between jet centerlines The bivariate interpolation algorithm was used to populate data for directivity angles forward of the measured data region and the last value was used to populate data for directivity angles downstream of the measured data region. It is recognized that extrapolation of data is inaccurate but without further information the extrapolation choices are considered acceptable for the system noise application. As expected the noise levels are lowest in the forward region that is fully shielded by the airframe (HWB body projection indicated by the light grey dots) and generally highest for larger polar angles. Figure $17 \mathrm{~b}$ shows the spectra for different polar angles for $\phi=0^{\circ}$. The scaled measurements do not contain data for the full frequency range from $50 \mathrm{~Hz}$ to $10 \mathrm{kHz}$. To define levels below the lowest measured frequency, the level at the lowest measured frequency was used down to $50 \mathrm{~Hz}$. For levels above the maximum measured frequency, a $-1.5 \mathrm{~dB}$ decrease per $1 / 3$-octave band to $4 \mathrm{kHz}$ and then a $-6 \mathrm{~dB}$ rate to $10 \mathrm{kHz}$ was used. The effect of this extension can be seen in Fig. 17b.

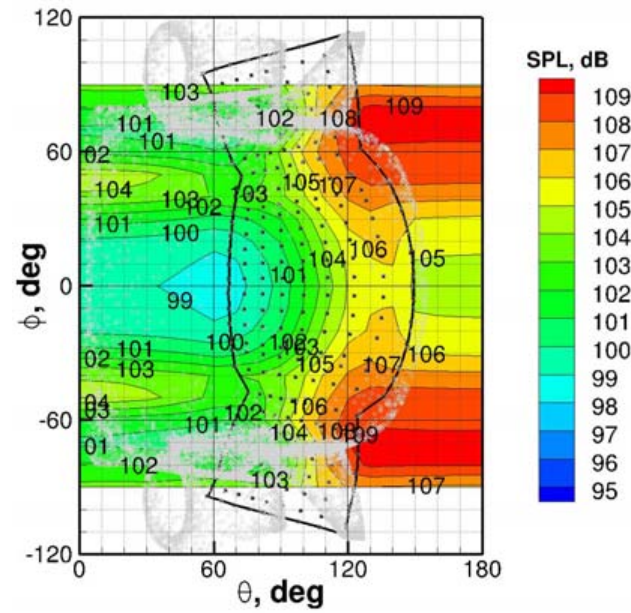

a) $f_{\mathrm{fs}}=\mathbf{5 0 0 H z}$

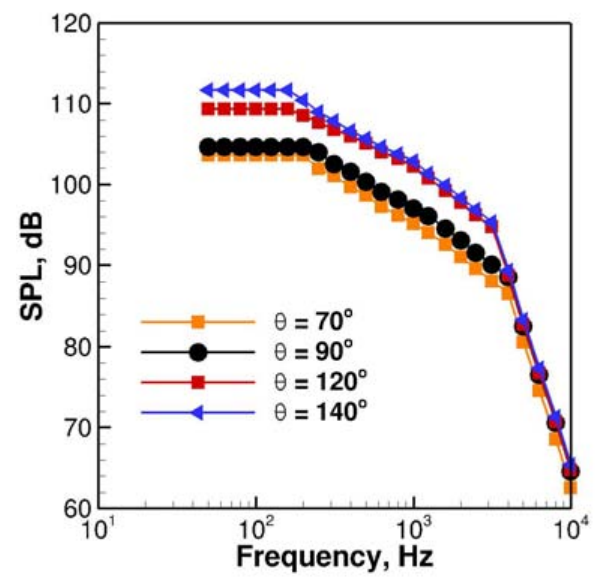

b) $\phi=\mathbf{0}^{\circ}$

Figure 17. Jet noise directivity $\left(R_{\mathrm{fs}}=15 \mathrm{ft}\right)$ and full-scale 1/3-octave spectra for the cutback condition.

\section{Importance of Aircraft Noise Component Ranking}

As discussed previously the ANOPP2 framework is used to compute the EPNL metric at each of the certification locations. Predicted and measured source noise are propagated to the certification reference points on the ground, where they are summed and tone-corrected to compute the PNLT time histories and subsequent EPNL metric. Obtaining accurate PNLT and EPNL metrics requires accuracy and confidence in the definitions, data, measurements and prediction methods used throughout the entire process. This includes flight profile definition (trajectory, aircraft configuration, operating condition), the associated engine states for each operating condition, accuracy of noise measurements, and predictions. For existing aircraft, data is often available to validate the predictions, giving confidence to the results. Performing these computations and verifying them for a concept aircraft is a particular challenge since data are often not available, particularly for validating the airframe and/or engine noise levels. Since engine noise is almost always dominant during takeoff (sideline and cutback segments), the correct component (core, fan inlet, fan exit and jet noise) levels and their relative ranking are critical in determining accurate overall noise levels. The N2A-EXTE engine is a concept engine without any known noise source ranking. However, based on observed trends in engine cycles, the EPNL source ranking of the GE90 at the 
cutback condition reported by Gliebe ${ }^{37}$ was used to adjust the relative source ranking of the N2A-EXTE engine at the full-throttle (SL) condition. The N2A-EXTE jet EPNL determined from the CJES measurements was then used to define the expected EPNL for the fan inlet, fan exit and core. The ANOPP source noise predictions for those sources (fan inlet, fan exit and core) were then calibrated (spectral noise levels adjusted uniformly) to force this ranking relative to the jet noise EPNL. The same relative ranking was used for the other flight conditions, since no other information was available.

\section{Noise Assessment Results}

The certification noise for the flight conditions of Table 2 is predicted. Two different approach conditions were developed to understand and assess noise changes due to variations in approach flight speed. The predictions were performed for a Baseline configuration as well as for configurations that provide additional noise mitigation using alternate vertical tail designs and location, Over-The-Rotor (OTR) and Soft Vane (SV) liner treatments for all fanrelated noise components (References 30-31). The Baseline configuration is defined with the engine exhaust positioned 2.5 fan exit diameters upstream of the airframe's trailing edge, nozzle chevrons ${ }^{13,22}$. high-lift drooped leading edge design and narrow chord vertical tails canted at $10^{\circ}$ in the aft location (see Fig. 2).

The Tone corrected Perceived Noise Levels (PNLT) time histories for each noise component and the total noise are plotted in Fig. 18 at each predicted measurement location. The ground reflections are included in the predictions.

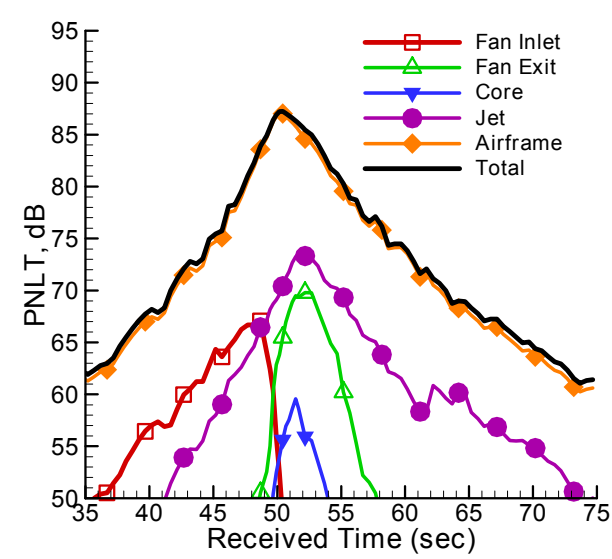

a) Approach (A1)

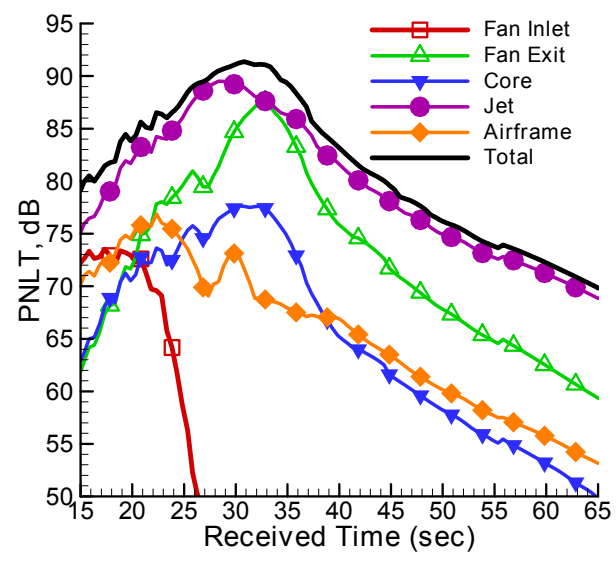

c) Takeoff (Sideline)

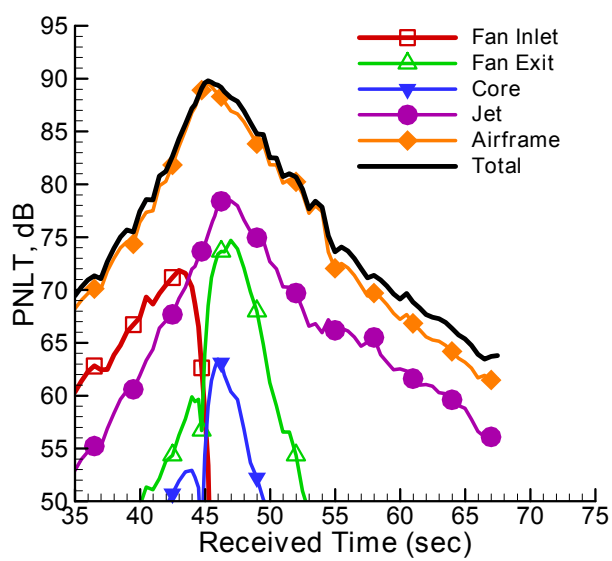

b) Approach (A2)

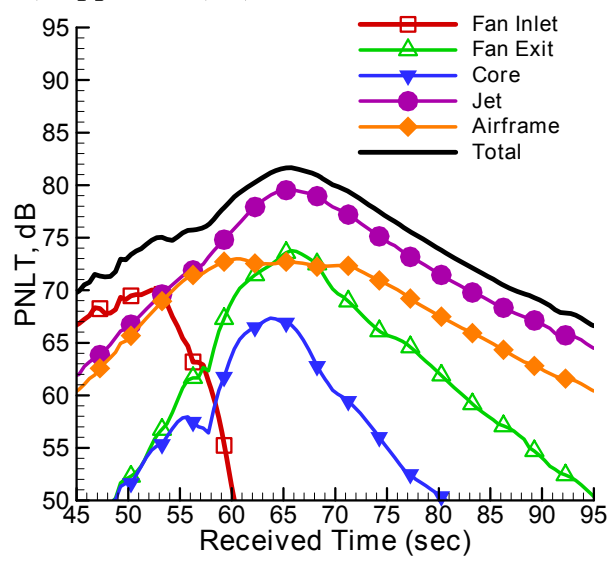

d) Flyover (Cutback)

Figure 18. Predicted PNLT time histories at the certification measurement points for the Baseline configuration. 
Time integration of the PNLT data is subsequently used to compute the associated EPNLs at each flight condition (A1, A2, SL and CB). Examination of the PNLT time histories provides insight to the component noise ranking at each measurement location. For the two approach conditions (A1 and A2), the airframe PNLT levels clearly dominate. As previously indicated by the component spectra of Fig. 14, the main gear is the dominant airframe source for these approach conditions, with the nose gear and inboard side-edges of the drooped leading edge providing some contribution. The engine noise levels are reduced due to low engine power settings and shielding of the engine sources by the airframe. For the sideline and flyover observer the jet noise component dominates. At sideline (Fig. 18c) the fan exit noise and to a lesser degree the core noise provide contributions to the overall noise level, with both the airframe and fan inlet contributing minimally. At the cutback, shown in Fig. 18d, the jet, airframe and fan exit noise components are the main contributors to the overall level. The main component of the airframe noise is most likely the inboard side-edges of the high-lift drooped LE.

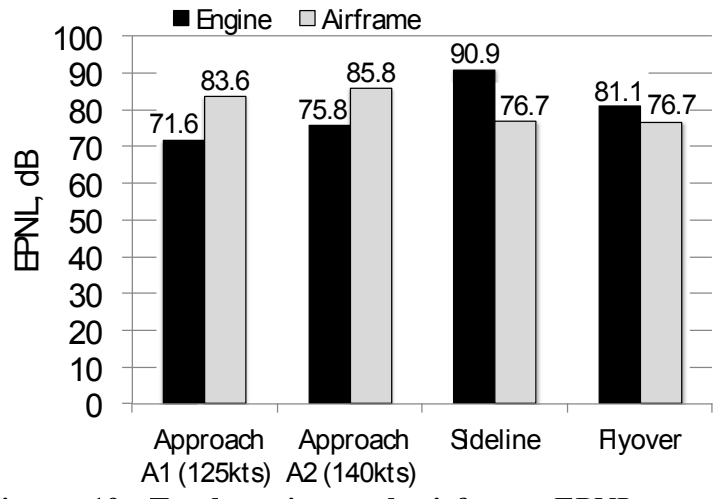

Figure 19. Total engine and airframe EPNL at each certification point for the Baseline configuration.
Figure 19 shows the separate totals for engine and airframe noise. As expected, the airframe noise dominates for the approach point, while the engine noise dominates for sideline and less for the flyover (cutback) point. This suggests that investments in noise technologies for the engine on takeoff and airframe on approach would be most be effective in reducing aircraft.

Two cumulative (CUM) noise metrics are then computed, differing by the approach EPNL used to compute the CUM. One CUM is computed by summing $\mathrm{A} 1$, SL and $\mathrm{CB}$ and the other is the sum of $\mathrm{A} 2$, SL and CB. The latter CUM definition, that includes A2, is representative of today's operations, in that current aircraft of this size approach landing at that higher speed. Both CUM levels relative to Stage 4 limits are shown in Fig. 20. The first two bars are for the Baseline configuration (identified as "Baseline vertical"). The CUM levels that include the A2 approach EPNL are about 2.5
EPNdB louder than the CUM level determined with the A1 approach EPNL. This comparison quantifies the potential noise benefit of reducing the approach speed. However, a number of issues would need to be examined before reduced approach speeds are found acceptable, including aircraft flight worthiness and safety, and impact on airport operations to name a few. But with a potential noise benefit of $2.5 \mathrm{EPNdB}$ this may be worth the consideration.

The remaining CUM levels shown in Fig. 20 are for configurations with progressively added noise technologies to the Baseline. The effect of alternate vertical tail designs and placement were examined in detail in Reference 21, with the most effective design being the narrow chord vertical canted at $30^{\circ}$ in the aft position (herein referred to as Alt. vertical). Replacing the Baseline vertical with the Alt. vertical reduces the CUMs (which increases the margin to Stage 4 shown in Fig. 20) by 0.3 EPNdB relative to the Baseline. This is shown by the second set of bars in Fig. 20. The Alt vertical decreases the fan exit and core noise and to a lesser degree jet noise (due to its distributed character) at the sideline measurement point.

The next two sets of bars in Fig. 20 assess noise benefit associated with the OTR/SV fan noise technologies. The benefit is estimated from analysis of experimental data $^{30.31}$ and applied to the appropriate fan source noise component as a

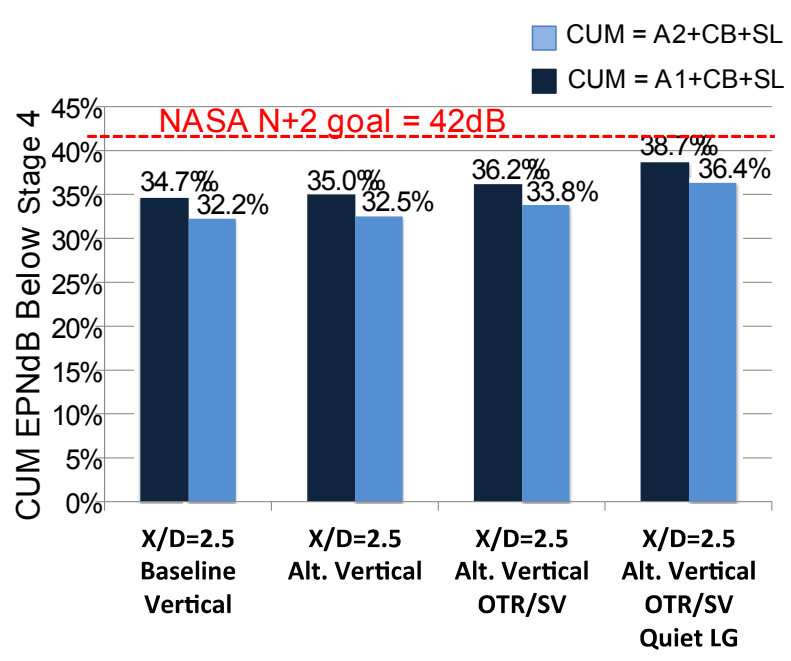

Figure 20. N2A-EXTE CUM noise results for variations in noise reduction strategies. 
spectral $\mathrm{dB}$ reduction. Inclusion of the fan noise technologies provides an additional 1.2 EPNdB of noise benefit, which results in 36.2 EPNdB below Stage 4. The last set of bars includes landing gear technologies in addition to the Alt. vertical, OTR and SV and is herein referred to as the 'best' configuration. The landing gear technology benefit accounts for shielding of gear components from the incoming flow and modifies the gear's geometry to reduce flow separation. Similar to the fan noise technologies, the benefit is applied to the main and nose landing gear as spectral $\mathrm{dB}$ reductions. The relative CUM level of this 'best' configuration is 38.7 EPNdB below Stage 4, with the A1 approach condition. If the CUM is computed using the A2 approach condition, the CUM level below Stage 4 is 36.4 EPNdB. It should be noted that the noise reductions realized for the installed jet and verticals are determined directly from the scaled acoustic measurements of the N2A-EXTE operating at the same flight conditions. This provides much confidence in the predicted aircraft noise levels, particularly for the Baseline HWB configuration with and without alternate verticals. The impact of the OTR/SV and quiet landing gear technologies on the overall aircraft weight and design was not part of the N2A-EXTE experimental studies and was not evaluated. However the potential noise benefits from those technologies are demonstrated through the system noise assessment process.

The 'best' configuration noise level in terms of PNLT time histories and EPNL totals for engine and airframe are shown in Figs 21 and 22, respectively. The PNLT time histories have nearly the same appearance as those presented for the Baseline configuration in Fig. 18. The differences are namely due to amplitude reductions associated with the noise technologies and not changes in the overall shape of the time histories. Figure 22 shows the separate totals for engine and airframe noise for the 'best' configuration. As expected the airframe noise dominates for the approach

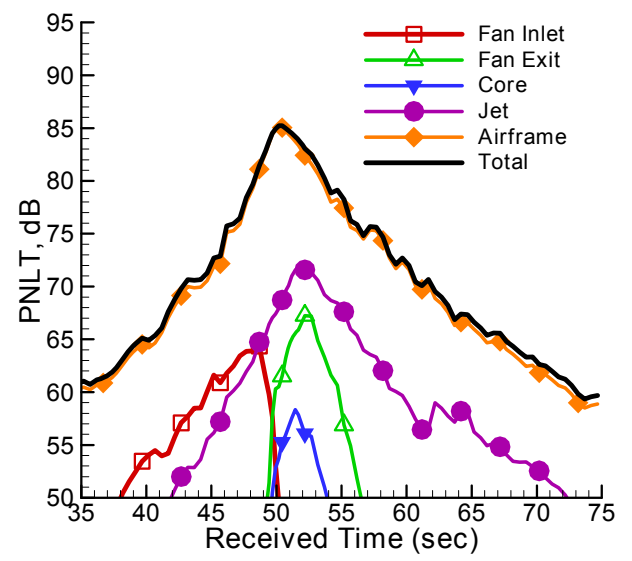

a) Approach (A1)

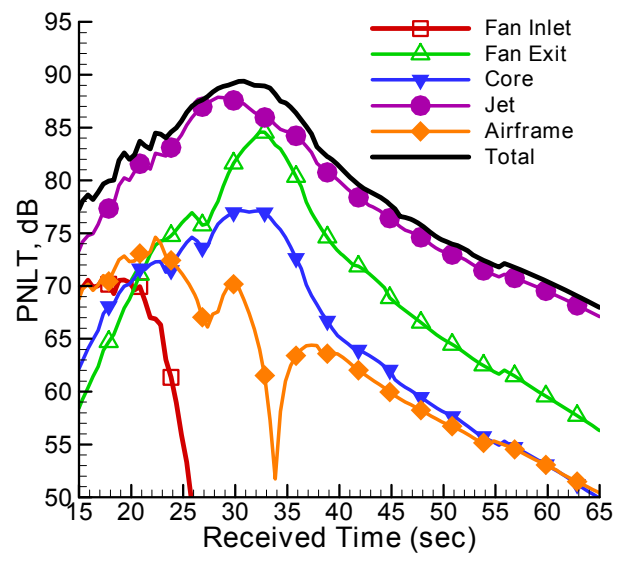

c) Takeoff (Sideline)

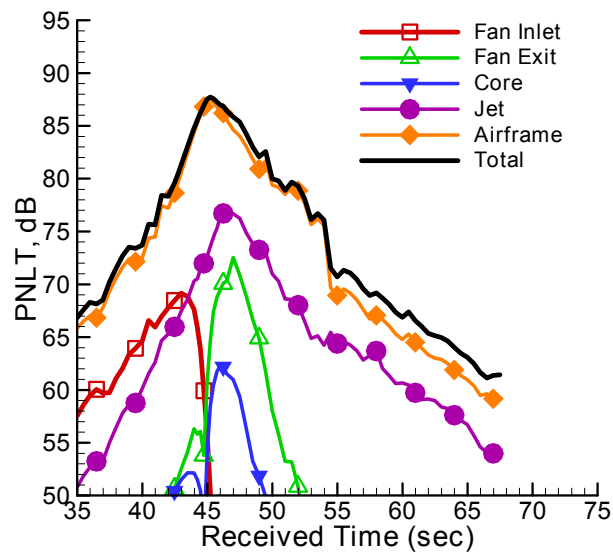

b) Approach (A2)

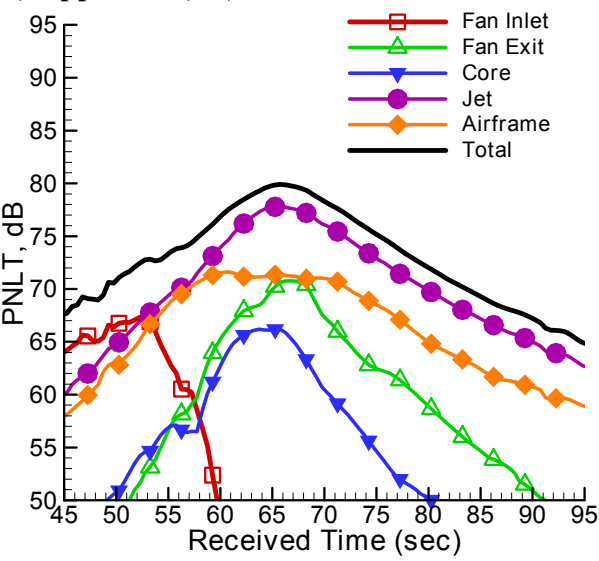

d) Flyover (Cutback)

Figure 21 Predicted PNLT time histories at the certification measurement points for the 'best' configuration. 
point and the engine noise dominates for sideline and less for the flyover (cutback) point. The reduction from the baseline configuration to the 'best' configuration is seen in both airframe and engine totals at all measurements points. This suggests that noise technologies for both engine and airframe can be effective in reducing the overall CUM levels. However the most promising reduction appears to be for engine sources on takeoff and airframe on approach.

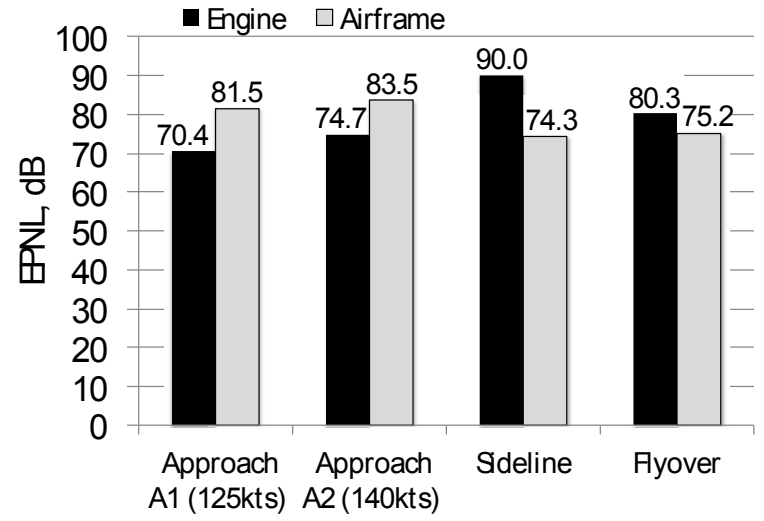

Figure 22. Total engine and airframe EPNL predicted at the certification point for the "best" configuration.
A. Comments with respect to previous studies The "best" configuration presented here assesses at 38.7 EPNdB below Stage 4, just 3.3 EPNdB below the NASA $\mathrm{N}+242 \mathrm{~dB}$ goal. In overall perspective, this new result shows that the NASA N+2 goal is achievable although probably more challenging compared to the previous HWB noise assessment reported by Thomas et al. $^{6}$ that showed a result slightly better than the $42 \mathrm{~dB}$ goal. There are several key differences between that previous study and the present and it is those detailed differences that contribute to one exceeding the goal and the other being just below the goal. One key difference is the propulsion system. In the previous study the GE90 engine was used and both its source noise breakdown and engine model were known with more confidence than for the current higher bypass ratio engine. Since engine noise dominates at the sideline and to a lesser degree at cutback for the

aircraft used in both studies, the EPNLs at those two locations are sensitive to the prediction of the engine noise. Small variations in the prediction of the engine sources can have a significant impact on the overall system noise. In the previous study, all isolated engine noise sources were predicted and measured engine shielding effects were applied to the engine components. All airframe sources were predicted with some adjustment to the ranking made according to measured results of Guo et al. ${ }^{38}$ In this study, the measured airframe noise and installed jet noise were used directly and only the fan and core sources were predicted with measured shielding applied. The measurements obtained for the N2A-EXTE were for a geometrically scaled-model of the vehicle, which included correct outer mold lines of the airframe and engine nacelles, and the model was positioned at non-zero angles-of-attack during testing. The previous study used a representative HWB planform airframe model without full 3D outer mold line although it did have realistic leading and trailing edges. The previous study also did not test at angle-of-attack, although a larger range of polar and azimuthal directivity noise measurements were obtained. The effect of each of these differences has not been thoroughly investigated but the cumulative effects are expected to explain many of the differences in the results of these two studies. In comparing the study of Thomas et al. ${ }^{6}$ with the present study it is also important to remember the differences in the framework of the two studies (with the study of Thomas et al. ${ }^{6}$ occurring several years earlier, focusing on the technology approach to achieving the $42 \mathrm{~dB}$ goal and developing to a high fidelity level the technology of jet shielding effectiveness). This type of thorough comparison was reported by Guo et al. ${ }^{39}$ when analyzing the study by Thomas et $a .^{6}$ and another recent and relevant study of the advanced Boeing HWB concept with ultra high bypass ratio engines.

\section{Conclusions}

This HWB system noise assessment study is a result of an effort by NASA to explore a realistic HWB design that has the potential to reduce simultaneously community noise and fuel burn substantially. The more than 5-year effort included the development of the Boeing N2A-EXTE aircraft design, design and fabrication of a detailed 5.8\% windtunnel model (with propulsive and airframe components), and subsequent extensive aerodynamic and acoustic testing by NASA. The test produced noise spectra and directivity data for the airframe, jet, and engine shielding for aircraft conditions of takeoff, cutback, and landing approaches. Analysis permitted direct scaling of the noise field to that of full-scale aircraft at the required certification measurement locations. Analysis and prediction required for turbomachinery specifics were summarized. The component noise spectra, PNLT level breakdown, and integrated CUM EPNL were evaluated. This was done for a baseline configuration and with several low noise strategies 
employed. Present results indicate that the lowest noise configuration would be within $3 \mathrm{~dB}$ of current NASA goals. These results continue to support that significant noise reduction in overall aircraft noise is achievable through configuration and operation changes.

\section{Acknowledgments}

The authors sincerely thank the entire $14 \times 22$ Tunnel test team for their efforts during these experiments, particularly test engineer Les Yeh and test coordinators Mr. Dan Hoad and Ms. Stephanie Heath. Mr. Jeff Berton for developing and providing the N2A-EXTE engine model and state parameters, Mr. John Rawls for his ANOPP support, and Dr. Russ Thomas for his insight of HWB system noise, noise reduction technologies and general considerations for propulsion airframe aeroacoustics. The authors acknowledge and thank the Environmentally Responsible Aviation Project within NASA's Integrated Systems Research Program for funding this research.

\section{References}

1. Liebeck R.H. "Design of the Blended-Wing-Body Subsonic Transport" AIAA Paper 2002-0002.

2. Hill, G., Brown, S., Geiselhart, K., and Burg, C., "Integration of Propulsion Airframe Aeroacoustic Technologies and Design Concepts for a Quiet Blended Wing Body Transport," AIAA-2004-6306.

3. Hileman J.I., Spakovszky Z.S., Drela M. \& Sargeant M.A. "Airframe Design for Silent Aircraft” AIAA-20070453.

4. Nickol C.L. \& McCullers L. "Hybrid Wing Body Configuration System Studies" AIAA Paper 2009-931.

5. Czech, M., Thomas, R., and Elkoby, R., "Propulsion Airframe Aeroacoustic Integration Effects of a Hybrid Wing Body Aircraft Configuration,” International Journal of Aeroacoustics, Vol. 11, Number 3+4, pp. 335-367, 2012.

6. Thomas, R.H, Burley, C.L., and Olson, E.D., "Hybrid Wing Body Aircraft System Noise Assessment With Propulsion Airframe Aeroacoustic Experiments," International Journal of Aeroacoustics, Vol. 11, Number 3+4, pp. 369-409, 2012.

7. Kawai, R.T. "Acoustic Prediction Methodology and Test Validation for an Efficient Low-Noise Hybrid Wing Body Subsonic Transport", Final report for NASA Contract Number NNL07AA54C (Feb. 2011).

8. DOT/FAA AC 36-4C - Noise Standards: Aircraft Type and Airworthiness Certification, July, 15, 2003.

9. DOT/FAA 14 CFR Parts 36 and 91: Stage 4 Aircraft Noise Standards, Federal Register: Volume 70, Number 127, July 5, 2005.

10. Gatlin, G.M., Vicroy, D.D., Carter, M.B., "Experimental Investigation of the Low-Speed Aerodynamic characteristics of a 5.8-Percent Scale Hybrid Wing Body Configuration”, AIAA-2012-2669.

11. Hutcheson, F.V., "Overview of the NASA Hybrid Wing Body Aeroacoustic Test", AIAA presentation at the $21^{\text {st }}$ Aeroacoustics Conference in Atlanta, GA (June 2014).

12. Heath, S.L., Brooks, T.F., Hutcheson, F.V., Doty, M.J., Bahr, C.J., Hoad, D.R., Becker, L.E., Humphreys, W.M., Burley, C.L., Stead, D.J., Pope, D.S., Spalt, T.B., Kuchta, D., Plassman, G.,Moen, J., "NASA Hybrid Wing Body Aircraft Aeroacoustic Test Data Report", NASA TM, 2014 (to be published).

13. Thomas, R. H., Czech, M. J., and Doty, M. J., "High Bypass Ratio Jet Noise Reduction and Installation Effects Including Shielding Effectiveness," AIAA Paper No. 2013-0541 presented at the $51^{\text {st }}$ AIAA Aerospace Sciences Meeting, January 2013.

14. Lytle, J.K., "The Numerical Propulsion System Simulation: An Overview," NASA TM 209915, 2000.

15. Lopes, L.,V., Burley, C.L., "Design of the Next Generation Aircraft Noise Prediction Program: ANOPP2," AIAA Paper no. 2011-2854, $17^{\text {th }}$ AIAA/CEAS Aeroacoustics Conference, Portland, Oregon, June 5-8, 2011.

16. Zorumski, William E., “Aircraft Noise Prediction Program Theoretical Manual,” NASA TM-83199, 1982.

17. Emmerling, J. J., Kazin, S. B., and Matta, R. K., "Core Engine Noise Control Program. Volume III, Supplement 1 - Prediction Methods," FAA-RD-74-125, III-I, Mar. 1976. (Available from DTIC as AD A030 376).

18. Gas Turbine Jet Exhaust Noise Prediction. SAE Aerospace Recommended Practice ARP876, Society of Automotive Engineers, January 1994.

19. Heidmann, M. F., "Interim Prediction Method for Fan Compressor Source Noise", NASA TM X-71763, 1979.

20. Krejsa, E. A. and Stone, J. R., "Enhanced Fan Noise Modeling for Turbofan Engines", Diversitech, Inc. Informal Report to NASA GRC Contract ID NNC05VD49P, December 31, 2005. 
21. Hutcheson, F.V., Brooks, T.F., Burley, C.L., Bahr, C.J., Stead, D.J., Pope, D.S., "Shielding of Broadband Turbomachinery Noise from a Hybrid Wing Body Aircraft Configuration", AIAA paper accepted for presentation at the $20^{\text {st }}$ Aeroacoustics Conference in Atlanta, GA (June 2014).

22. Doty, M.J., Brooks, T.F., Burley, C.L., Pope, D.S., "Jet Noise Shielding Provided by a Hybrid Wing Body Aircraft", AIAA paper accepted for presentation at the $20^{\text {st }}$ Aeroacoustics Conference in Atlanta, GA (June 2014).

23. McCullers, L. A.: "FLOPS Weight Module Documentation, Wate.doc," FLOPS Users Manual, updated April 2008.

24. Nickol, C. L. and McCullers, L. A., "Hybrid Wing Body Configurations System Studies," AIAA Paper No. 2009-931.

25. Brooks, T. F., and Humphreys, W. M., Jr., “A Deconvolution Approach for the Mapping of Acoustic Sources (DAMAS) Determined from Phased Microphone Arrays", Journal of Sound and Vibration, Vol. 294, 2006, pp. 856-879.

26. Humphreys, W. M., Jr., Brooks, T. F., Bahr, C. J., Spalt, T. B., Bartram, S. M., Culliton, W. G., and Becker, L. E., "Development of a Microphone Phased Array Capability for the Langley 14- by 22 Foot-Subsonic Tunnel," AIAA Paper accepted for presentation at the $20^{\text {th }}$ Aeroacoustics Conference in Atlanta, GA (June 2014).

27. Spalt, T. B., Brooks, T. F., Bahr, C. J., Plassman, G. E., Becker, L. E., and Stead, D. J., "Calibrations of the NASA Langley 14- by 22-Foot Subsonic Tunnel in Acoustic Configuration," AIAA Paper accepted for presentation at the $20^{\text {th }}$ Aeroacoustics Conference in Atlanta, GA (June 2014).

28. Bahr, C. J., Brooks, T. F., Humphreys, W. M., Jr., Spalt, T. B., and Stead, D. J., "Acoustic Data Processing and Transient Signal Analysis for the Hybrid Wing Body 14- by 22-Foot Subsonic Wind Tunnel Test," AIAA Paper accepted for presentation at the $20^{\text {th }}$ Aeroacoustics Conference in Atlanta, GA (June 2014).

29. Brooks, T. F., "Aeroacoustic Scaling Principles and the Hybrid Wing Body Test", Keynote Address, 17th AIAA/CEAS Aeroacoustics Conference, Portland, OR, June 6-8, 2011.

30. Sutliff, D.L.; Jones, M.G.; Hartley, T.C.: Attenuation of FJ44 Turbofan Engine Noise with a Foam-Metal Liner Installed Over-the-Rotor. 15th AIAA/CEAS Aeroacoustics Conference, AIAA-2009-3141, 2009.

31. Jones, M.; Parrott, T.; Sutliff, D.; Hughes, C.: Assessment of Soft Vane and Metal Foam Engine Noise Reduction Concepts. 15th AIAA/CEAS Aeroacoustics Conference, AIAA-2009-3142, 2009.

32. Ravetta P. A., Burdisso R. A., Ng W. F., Khorrami M. R. \& Stoker R. W. "Screening of Potential Noise Control Devices at Virginia Tech for QTD II Flight Test" AIAA 2007-3455, 2007.

33. Bozak, R., and Henderson, B., “Aeroacoustic Experiments with Twin Jets," AIAA Paper No. 2011-2790 presented at the $17^{\text {th }}$ AIAA/CEAS Aeroacoustics Conference, June 2011.

34. Doty, M. J., "Investigation of Twin Jet Aeroacoustic Properties in the Presence of a Hybrid Wing Body Shield," AIAA Paper No. 2012-2157 presented at the 18 ${ }^{\text {th }}$ AIAA/CEAS Aeroacoustics Conference, June 2012.

35. Dobrzynski W., Chow L. C., Smith M., Boillot A., Dereure O. \& Molin N. "Experimental Assessment of Low Noise Landing Gear Component Design” AIAA Paper 2009-3276, 2009.

36. Dobrzynski W., Chow L. C., Guion P. \& Shiells D "Research into Landing Gear Airframe Noise Reduction" AIAA 2002-2409, 2002.

37. Gliebe, Philip R., "The GE90: Quiet by Design" Quieter Aircraft Engines Through Leveraging New Technologies," Presentation for 2003 Berkeley Airport Noise Symposium Doing the Wright Stuff: 100 years of Aviation and the Environment, http://www.its.berkeley.edu/techtransfer/events/air/2003/pdf/gliebe03.pdf, March $11,2003$.

38. Guo, Y., Brusniak, L., Czech, M., and Thomas, R., "Hybrid Wing-Body Aircraft Slat Noise," AIAA Journal, Vol. 51, pp. 2935-2945, DOI: 10.2514/1.J052540, 2013.

39. Guo, Y., Burley, C., and Thomas, R., "On Noise Assessment for Blended Wing Body Aircraft," AIAA Paper No. 2014-365, January 2014. 


\author{
Filename: 1f99-17725_final-Burley_AeroacousticConf_v30 \\ Directory: $\quad$ C: $\backslash$ Users $\backslash w \bar{b}$ aize $\backslash A p p D a t a \backslash L o c a l \backslash T e m p \backslash 2$ \\ Template: \\ C: IUsers\wbaize \AppData\Roaming \Microsoft $\backslash$ Templates $\backslash$ Normal. \\ $\operatorname{dotm}$ \\ Title: \\ Measurement methods of Trailing Edge Noise \\ Subject: \\ Author: \\ Keywords: \\ Comments: \\ Creation Date: $\quad$ 5/21/2014 8:10:00 AM \\ Change Number: 2 \\ Last Saved On: $\quad$ 5/21/2014 8:10:00 AM \\ Last Saved By: \\ Total Editing Time: 2 Minutes \\ Last Printed On: $\quad$ 7/10/2014 1:14:00 PM \\ As of Last Complete Printing \\ Number of Pages: 21 \\ Number of Words: $\quad 9,870$ (approx.) \\ Number of Characters: $\quad 56,264$ (approx.)
}

